Article

\title{
Lessons Learnt from the Application of MCDA Sorting Methods to Pipe Network Rehabilitation Prioritization
}

\author{
João Caetano ${ }^{1, *(\mathbb{D}}$, Nelson Carriço $^{1}(\mathbb{D})$ and Dídia $\operatorname{Covas}^{2}$ (1) \\ 1 ESTBarreiro and INCITE, Polytechnic Institute of Setúbal, 2839-001 Barreiro, Portugal; \\ nelson.carrico@estbarreiro.ips.pt \\ 2 CERIS, Instituto Superior Técnico, Universidade de Lisboa, 1049-001 Lisbon, Portugal; \\ didia.covas@tecnico.ulisboa.pt \\ * Correspondence: joao.pedro.caetano@tecnico.ulisboa.pt
}

check for updates

Citation: Caetano, J.; Carriço, N.; Covas, D. Lessons Learnt from the Application of MCDA Sorting Methods to Pipe Network Rehabilitation Prioritization. Water 2022, 14, 736. https://doi.org/ $10.3390 / w 14050736$

Academic Editor: Mashor Housh

Received: 28 December 2021

Accepted: 23 February 2022

Published: 25 February 2022

Publisher's Note: MDPI stays neutral with regard to jurisdictional claims in published maps and institutional affiliations.

Copyright: (C) 2022 by the authors. Licensee MDPI, Basel, Switzerland. This article is an open access article distributed under the terms and conditions of the Creative Commons Attribution (CC BY) license (https:// creativecommons.org/licenses/by/ $4.0 /)$.

\begin{abstract}
Most water distribution networks were built a few decades ago, showing symptoms of deterioration. Additionally, current renewal rates are insufficient to overcome pipe networks' continuous ageing process. The development of methodologies for assisting the definition of pipe rehabilitation, including which pipes, and when and what financial amounts to allocate to this activity, are of the utmost importance. These methodologies typically have to attend to several points of view, for which multicriteria decision analysis (MCDA) techniques may be used. The current paper demonstrates and discusses the application of two MCDA techniques-the ELECTRE TRI-C and FlowSort-to a real water distribution network. Both techniques allowed assigning every single pipe to a predefined priority category, although the ELECTRE TRI-C proved to be more effective. These approaches imply that the planning of investment needs is carried out based on individual pipes, but these approaches are not consistent with the actual rehabilitation projects. A clustering technique called affinity propagation, together with cost functions, were applied to define and quantify homogeneous rehabilitation units. Even so, the methodology did not prove to be rigorous enough for the selection of pipes to be rehabilitated. On the other hand, it proved effective to estimate annual budgets for rehabilitation.
\end{abstract}

Keywords: water distribution networks; rehabilitation; condition assessment; decision-making process; multicriteria decision analysis

\section{Introduction}

Nowadays, water utilities are facing major challenges related to the assessment of the rehabilitation needs and the operational management of their assets, in particular in water distribution networks (WDN) composed of many old and leaky pipes [1]. Despite rehabilitation works, the average renewal rate is often insufficient to cope with accelerated and continuous ageing networks [2]. The integrity of many WDNs is seriously compromised, as these systems have accumulated alarming levels of deferred rehabilitation [3]. This fact can lead to several problems, such as high leakage levels, frequent bursts, interruption or inadequate service provision, unacceptable water quality levels, increased system maintenance requirements, and operational costs, that can seriously compromise the continuity of the service and the sustainability of the infrastructure $[4,5]$.

Managers are currently facing the challenge of prioritizing the assets that need rehabilitation, based on insufficient knowledge and data, as it is not feasible to simultaneously rehabilitate all pipes in a WDN in the same year given the budget constraints [6]. These assets are subjected to different deterioration mechanisms that interfere with their natural ageing processes. Additionally, their conditions cannot be easily and directly assessed through visual inspection, since these assets are buried and the service may not be disrupted, turning the inspection into an impractical process [7]. Thus, the condition of every 
asset must be inferred through other measurable parameters, taking into account several points of view (e.g., hydraulic, structural) and assessment criteria and metrics (e.g., residual life, velocity, number of failures, pipe material) [2].

Dealing with a problem that embraces different points of view and assessment criteria requires the use of aggregation techniques that can simultaneously cover all the different issues at stake. This problem can be solved through the field of multicriteria decision analysis (MCDA), which provides techniques to aid in decisions in complex problems under high uncertainty scenarios and conflicting criteria, described by different types of data, multiple interests and perspectives [8].

The selection process of the MCDA technique strongly depends on the decision-maker expected outcome. Therefore, in the field of MCDA, the term problematic is used to refer to the way in which decision aid is envisaged. Roy (2005) distinguishes four types of decision problematics: selection (e.g., selection of the best option based on a comparative evaluation between options); ranking (e.g., options ordering based on a comparative evaluation); sorting (e.g., assigning options into classes with identical characteristics); description (e.g., the decision problem formulation). Only the first three problematics apply to the WDN rehabilitation problem [9].

Several MCDA techniques referring to distinct problematics have been applied in the context of rehabilitation of WDN assets, namely: the definition of priorities for a set of WDN rehabilitation projects using ELECTRE and Additive Weighting [10]; the definition of rehabilitation priorities for sets of pipes (i.e., water distribution blocks) using ELECTRE II and AHP [11]; the combination of a pipe failure model with the rehabilitation model to define rehabilitation strategies [12]; and the comparison of MCDA techniques (i.e., AHP, WSM, ELETRE, PROMETHEE, TOPSIS) for the application in integrated rehabilitation management, including several types of infrastructure (i.e., gas, water, wastewater) [13]. However, none of these applications aims to assign pipes to priority categories for rehabilitation using MCDA methods that deal with the sorting problematic.

This paper aims at the application and discussion of the MCDA approach developed by Carriço et al., 2021 [4] to a real-life case study, focusing on the problem evaluation stage where the assessment metrics are established. Two methods from the ELECTRE and PROMETHEE families are used, namely, the ELECTRE TRI-C [14] and the FlowSort [15]. The investment needs for the rehabilitation of the WDN within a 15-year horizon are defined based on the pipe assignment results to each priority category. Additionally, an unsupervised clustering technique called Affinity Propagation (AP) is applied in order to aggregate individual pipes into groups with similar characteristics.

Despite several research works having been published in the application of sorting MCDA methods to pipe rehabilitation (i.e., ELETRE TRI-C and FlowSort), these methods require the specification of boundaries between two consecutive categories. These boundaries are difficult to define by the water utility managers that often have a fuzzy idea of their meaning. The main innovative feature of this article is the application of a sorting methods to this decision problem, using reference pipes to describe the representative characteristics of each priority category. Thus, these methods facilitate the process of defining categories, as they use real pipe characteristics to represent them, allowing the utility managers to use their daily experience in the decision model.

\section{Methodology}

\subsection{Methodology Description}

The MCDA methodology applied in this paper was developed by Carriço et al., 2021 [4] and comprises three distinct phases: problem identification, structuring, and evaluation. This article will essentially focus on the last phase of the methodology that is the problem evaluation. A brief description of each phase will be presented to contextualize the developments carried out herein. 
It is essential to mention that this methodology requires continuous interaction between the analyst and the utility experts and managers to whom the study is developed. Thus, from now on, the utility experts and managers will be called decision-makers (DM).

The problem identification phase allows the clarification of the decision problem to be addressed. There are several ways in which this problem can be identified but, in the present paper, it was identified during the development of the water utility infrastructure asset management (IAM) plan. The analyst and the DM carried several meetings to analyze the problem in detail. An IAM plan includes a diagnostic phase that allows assessing the condition of assets, identifying anomalies and symptoms, as well as analyzing the possible causes. This phase demonstrates the advanced state of deterioration of the pipes, as a result of the pipe ageing process. The main findings and conclusions attained in this phase are fundamental for structuring the decision problem. Increasing the integrity of the infrastructure becomes the main objective of the DM. In this sense, it is necessary to define the pipes that are candidates for rehabilitation, given that there are financial restrictions that do not allow the rehabilitation of the entire WDN at once. The candidate pipes for rehabilitation will be categorized to define their intervention priorities. This problematic type is called sorting problematic.

After structuring the decision problem, the evaluation phase is carried out, which comprises the establishment of assessment metrics, the selection of an aggregation method, its application, the sensitivity and robustness analysis, and the elaboration of final recommendations. This article aims to explore the application and comparison of two different methods. The results obtained on each priority category from each method are converted into future investments. The total and the annual budgets to rehabilitate the WDN in a period of 15-years are calculated using the capital cost functions developed by Covas et al. (2018) [7].

\subsection{MCDA Sorting Methods}

\subsubsection{Types of Methods}

The allocation of actions to predefined categories is a problem of great interest in many research areas, including risk assessment [16-19], environmental assessment [20-23], and maintenance management [24-27], having already been applied to sanitary sewer systems $[25,28]$. These techniques are called classification or sorting, depending on whether the categories are nominal or ordinal, respectively [29].

Sorting MCDA techniques help the decision-makers to assign a given action to an ordered category, previously defined based on their evaluation of a coherent family of criteria [30]. Notice that a sorting method is not intended to discover categories [31].

Generally, in a pipe rehabilitation decision-making process, the assessment is typically carried out by the utility experts (e.g., engineers) who manage the infrastructure, but the final decision is often made by the board of directors of the utility, who is truly the decision-maker.

The literature presents a wide range of interesting publications about sorting techniques and their applications to real-world decision-making problems [16,20,24,32]. From these publications, the one made by Alvarez et al., 2021 [33] is highlighted, since they carried out a systematic review of the MCDA sorting methods developed and applied in the last 30 years of research in the field. The authors have divided the methods into four distinct categories: full aggregation approach, goal aspiration or reference-level approach, non-classical MCDM approach, and outranking approach.

The outranking approach has the highest number of publications, representing $48 \%$ of the total publications [33]. This fact demonstrates that this approach is robust and mature for solving sorting problems. The most used methods are those from the family of ELECTRE (i.e., ELECTRE TRI-B, ELECTRE TRI-C, ELECTRE TRI-nC) and PROMETHEE (i.e., FlowSort, PROMSORT), this is the reason why the ELECTRE TRI-C and FlowSort methods were selected and applied to the case study in this paper. This paper aims at comparing the results obtained by the two different sorting methods, one from the 
ELECTRE family and the other from the PROMETHEE family, to better understand which of these better applies to the pipe rehabilitation prioritization problem.

\subsubsection{Pseudo-Criterion Model}

The methods of the ELECTRE and PROMETHEE families use a pseudo-criterion model to evaluate the assertion of "action a is at least as good as action $\mathrm{a}^{\prime \prime}$ " denoted $\mathrm{aS}_{\mathrm{j}} \mathrm{a}^{\prime}$. The pseudo-criterion model intends to consider the imperfect nature of the data by using the indifference $q_{j}$ and preference $p_{j}$ thresholds associated with each criterion $g_{j}$, such that $p_{j} \geq q_{j} \geq 0$. From this model, one of the following binary relations must be identified: indifference, weak preference, strong preference, or incomparability, as follows [30]:

1. $\quad \mathrm{aI}_{\mathrm{j}} \mathrm{a}^{\prime}:\left|\mathrm{g}_{\mathrm{j}}(\mathrm{a})-\mathrm{g}_{\mathrm{j}}\left(\mathrm{a}^{\prime}\right)\right| \leq \mathrm{q}_{\mathrm{j}}$, in this situation there is no significant advantage to differentiate the two actions, meaning that $\mathrm{a}$ is indifferent to $\mathrm{a}^{\prime}$ according to a specific criterion $\mathrm{g}_{\mathrm{j}}$.

2. $\quad a P_{j} a^{\prime}: g_{j}(a)-g_{j}\left(a^{\prime}\right)>p_{j}$, in this situation, there is a significant advantage of a over $a^{\prime}$, meaning that $a$ is strictly preferred to $a^{\prime}$ according to a specific criterion $g_{j}$.

3. $a Q_{j} a^{\prime}: q_{j}<g_{j}(a)-g_{j}\left(a^{\prime}\right) \leq p_{j}$, in this situation represents a zone of ambiguity meaning that the advantage of a over $a^{\prime}$ is a little large to fulfil over an indifference between $a$ and $a^{\prime}$, but this advantage is not necessary to fulfil over the strict preference in favor of a. In that case, $a$ is weakly preferred to $a^{\prime}$.

The DM can set the indifference and the preference threshold to null if he does not want or is unable to define them. In this case, the model used is called quasi-criterion. In a quasi-criterion model, any difference of performances in favor of one of two actions over the other, can be considered as significant for a strict preference on a criterion $g_{j}$. However, this should be considered unrealistic as it is not representative of a real decision problem. Furthermore, it does not take advantage of the full potential of the pseudo-criterion model.

\subsubsection{Prioritization Categories}

A sorting problem involves a set of $m$ actions: $A=\left\{a_{1}, \ldots, a_{m}\right\}$. Herein, an action is a rehabilitation intervention in a single pipe. Each action is evaluated on a set of $n$ criteria, $\mathrm{G}=\left\{\mathrm{g}_{1}, \ldots, \mathrm{g}_{\mathrm{n}}\right\}$, and each action is assigned to $k$ prioritization categories, $\mathrm{C}=\left\{\mathrm{C}_{1}, \ldots, \mathrm{C}_{\mathrm{k}}\right\}$.

Sorting the actions requires them to be compared to the reference profiles that distinguish the categories. Each category is defined by one or more reference profiles, which can be either central or limiting profiles. A central profile is described by a fictitious action characterized by certain performance values in each criterion. A limiting profile is similar to a central profile but it is used to define the boundaries of the categories. When using limiting profiles, $l p$, described by performance values $\left(\operatorname{lp}_{1}, \ldots, l p_{j}, \ldots, l p_{k-1}\right)$, the category $C_{j}$ is delimited by the lower limit profile $l p_{j}$ and the upper limit profile $l p_{j+1}$, which is also the lower limit profile of the category $C_{j+1}$. When using central profiles (or centroids), $c p$, described by performance values $\left(\mathrm{cp}_{1}, \ldots, c \mathrm{p}_{\mathrm{j}}, \ldots, c \mathrm{p}_{\mathrm{k}}\right)$, the category $\mathrm{C}_{\mathrm{j}}$ is characterized by tolerance distances to the performance values of the respective central profile. For the sake of generalization, hereafter, $\mathrm{R}=\left\{\mathrm{r}_{1}, \ldots, \mathrm{r}_{\mathrm{k}+1}\right\}$.

In the pipe rehabilitation prioritization case, a sorting method will evaluate every single candidate for rehabilitation from set A, according to the criteria of set $G$, and assign them to a category of set $C$. Figure 1 presents the generic case of applying a sorting method to pipes that are candidates for rehabilitation in WDN. 


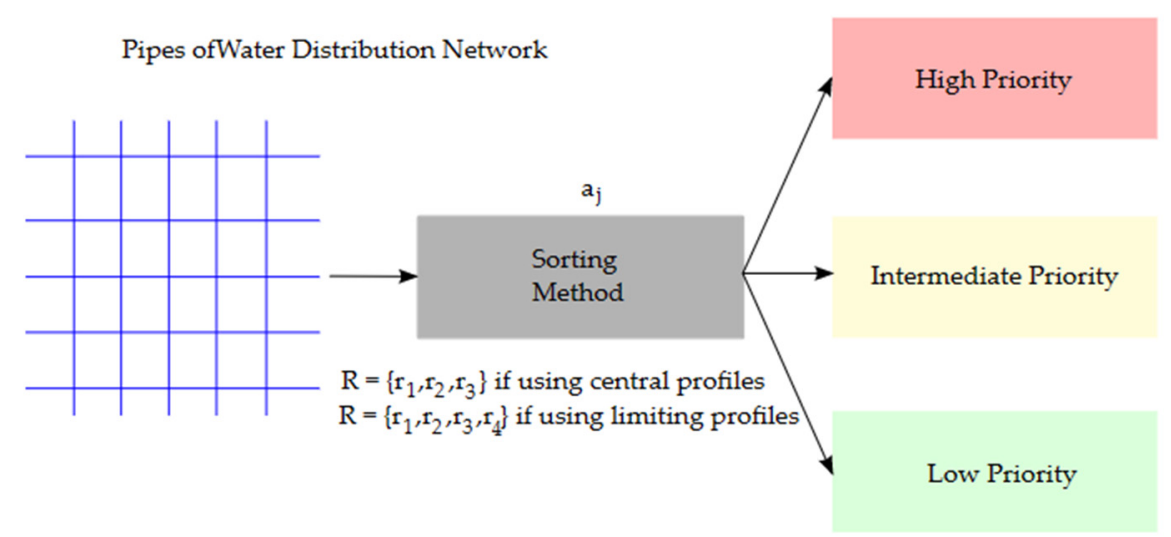

Figure 1. Generic case of applying a sorting method in WDN when using three categories.

\subsubsection{FlowSort Method}

The FlowSort method was developed in 2007 by P. Nemery [15], being an extension of the PROMETHEE method developed by J. P. Brans, in 1982 [34]. PROMETHEE is based on the concept of preference degrees allowing to solve raking problematics. The FlowSort method approaches the problematic of sorting as a ranking method. This method assigns actions to categories based on the relative position of an action with respect to reference profiles. This method, unlike the ELECTRE TRI-B or ELECTRE TRI-C, allows defining reference profiles of either limiting or central profiles [35].

The preference degrees used by these methods allow the DM to express how one action is preferred to another action or a reference profile. These preference degrees are calculated by applying a preference function and are intended to represent the intensity of preference varying between 0 to 1 [36]. There are six different types of widely accepted and used preference functions, as presented in Table 1 [37].

Table 1. Types of preference functions in the PROMETHEE methods.

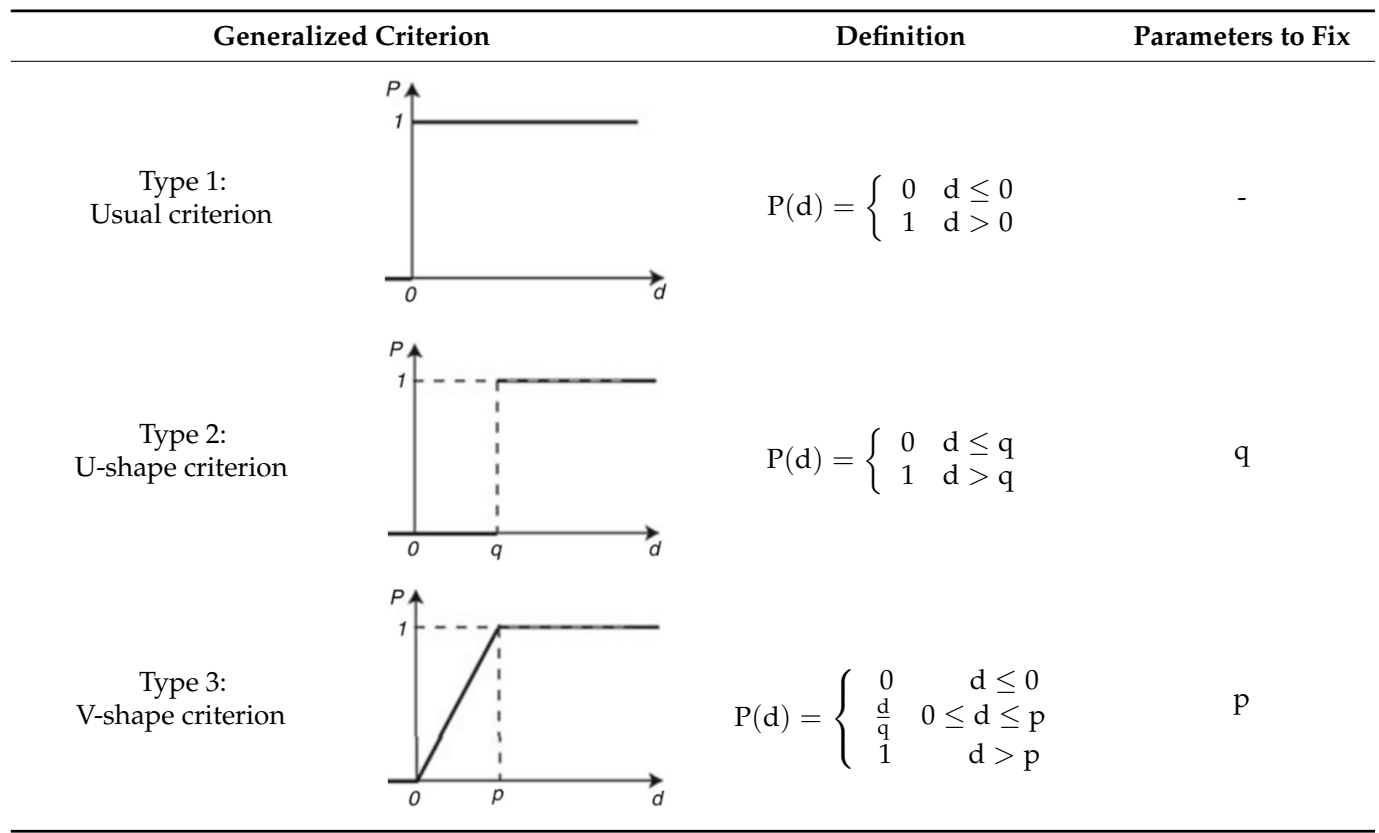


Table 1. Cont.

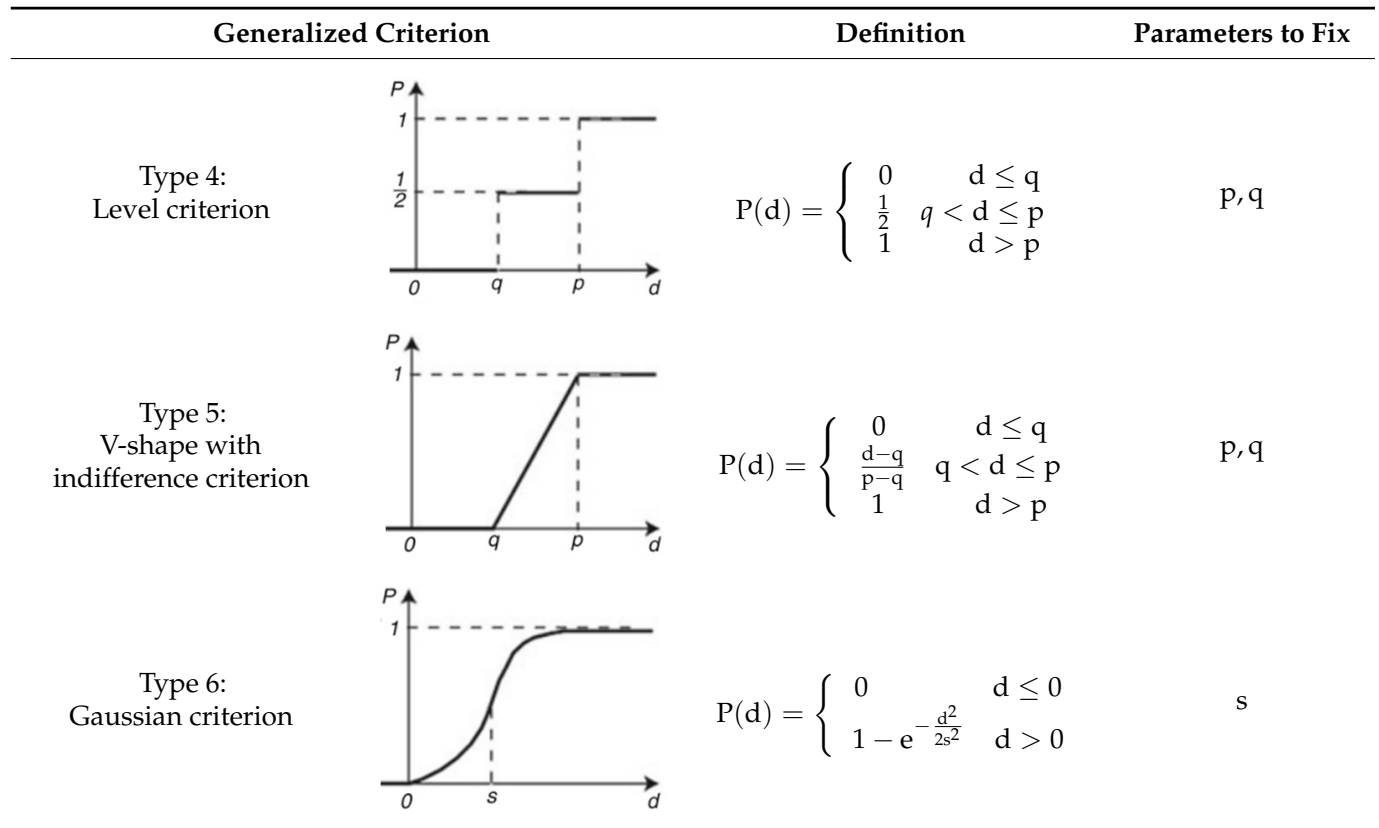

Legend: $\mathrm{p}$-indifference threshold; $\mathrm{q}$-indifference threshold; $\mathrm{d}$-difference between the actions and reference profiles that characterize a category, $\mathrm{s}-$ inflexion point.

The application of the FlowSort method requires that the DM understands the difference between the actions and the reference profiles that characterize a category in each specific criterion. The DM preference model needs the definition of two variables, namely the indifference threshold $\mathrm{q}$ and the preference threshold $\mathrm{p}$. The indifference threshold ranges from 0 , when there is no preference, to $p$, when a strict preference exists, the total preference is for $p$ equal to 1 [37]. The calculation of preference degrees, $\pi$, of action $a_{i}$ weighted by the respective coefficients of importance, $\mathrm{w}_{\mathrm{j}}$, is calculated as follows:

$$
\left\{\begin{aligned}
\pi\left(a_{i}, y\right) & =\sum_{j=1}^{n} P_{j}\left(a_{i}, y\right) w_{j} \\
\pi\left(y, a_{i}\right) & =\sum_{j=1}^{n} P_{j}\left(y, a_{i}\right) w_{j}
\end{aligned}\right.
$$

Due to the difficulty of having conclusions through the preference degrees, these can be summarized in the so-called global positive flows, global negative flows, and global net flows.

These scores measure the degree an action is preferred to a reference profile when they are compared and, contrariwise, i.e., the degree a reference profile is preferred to an action.

The global positive flows, global negative flows, and global net flow as described as follows [36]:

$$
\begin{gathered}
\Phi_{\mathrm{R}_{\mathrm{i}}}^{+}\left(\mathrm{a}_{\mathrm{i}}\right)=\frac{1}{\left|\mathrm{R}_{\mathrm{i}}\right|-1} \sum_{\mathrm{y} \in \mathrm{R}_{\mathrm{i}}} \pi\left(\mathrm{a}_{\mathrm{i}}, \mathrm{y}\right) \\
\Phi_{\mathrm{R}_{\mathrm{i}}}^{-}\left(\mathrm{a}_{\mathrm{i}}\right)=\frac{1}{\left|\mathrm{R}_{\mathrm{i}}\right|-1} \sum_{\mathrm{y} \in \mathrm{R}_{\mathrm{i}}} \pi\left(\mathrm{y}, \mathrm{a}_{\mathrm{i}}\right) \\
\Phi_{\mathrm{R}_{\mathrm{i}}}\left(\mathrm{a}_{\mathrm{i}}\right)=\Phi_{\mathrm{R}_{\mathrm{i}}}^{+}\left(\mathrm{a}_{\mathrm{i}}\right)-\Phi_{\mathrm{R}_{\mathrm{i}}}^{-}\left(\mathrm{a}_{\mathrm{i}}\right)
\end{gathered}
$$

where $R_{i}$ represents the set of reference profiles and $\pi\left(a_{i}, y\right)$ the preference degree of each action over the reference profiles.

Note that, although the flow values of the reference profiles directly depend on the action $\mathrm{a}_{\mathrm{i}}$, their order always respects the order of the categories. This allows delimiting a 
category $C_{h}$ by the flow values of $r_{h}$ and $r_{h+1}$ in case of categories defined by an upper and lower limit. Alternatively, a category defined by a central profile is represented by the flows of that central profile in respect to the other central profiles

There are two alternative ways to rank actions with respect to reference profiles: to calculate global positive $\Phi_{\mathrm{R}_{\mathrm{i}}}^{+}$and negative flows $\Phi_{\mathrm{R}_{\mathrm{i}}}^{-}$when using the PROMETHEE I method; and to calculate global net flows $\Phi_{\mathrm{R}_{\mathrm{i}}}$ when using the PROMETHEE II method. The former provides a partial ranking of actions and reference profiles and the latter a complete ranking. Brans and Vincke [38] recommend that both methods should be applied because the partial ranking allows identifying situations of incomparability, despite the complete ranking being, generally, easier to use. In other words, these methods are complementary.

In the case of PROMETHEE I, two distinct assignment rules are obtained, one based on the positive flows, $\mathrm{C}_{\Phi^{+}}\left(\mathrm{a}_{\mathrm{i}}\right)$, and the other based on the negative flows, $\mathrm{C}_{\Phi^{-}}\left(\mathrm{a}_{\mathrm{i}}\right)$. Actions are assigned to the corresponding category, by assessing whether the action $\mathrm{a}_{\mathrm{i}}$ is "preferred to" and "being preferred" to the reference profiles through global positive flows $\Phi^{+}\left(a_{i}\right)$ and global negative flows $\Phi^{-}\left(a_{i}\right)$. In the first rule, the action is assigned to the category $C_{h}$, if the flow $\Phi^{+}\left(\mathrm{a}_{\mathrm{i}}\right)$ is contained in the range defined by the positive flows of the reference profiles of category $C_{h}$. On the other hand, in the second rule, the action is assigned to the category $C_{h}$, if the flow $\Phi^{-}\left(a_{i}\right)$ is contained in the range defined by the negative flows of the reference profiles of category $C_{h}$.

In the PROMETHEE II ranking case, a single assignment considering the net flows can be defined.

Assigning an action to a category defined by central profiles is also possible. In this case, their flows are compared with the flows of the central profiles and an action is assigned to the category whose central profile has similar flows. The idea behind this concept is identical to the situation in which boundary profiles are used. Thus, in the first rule, the action is assigned to the category whose central profile has the same "preferred character". The second rule is based on "being the preferred character" of the action. As in the case of boundary profiles, based on the two different assignments rules, two possible categories $\widetilde{\mathrm{C}}_{\Phi^{+}}\left(\mathrm{a}_{\mathrm{i}}\right)$ and $\widetilde{\mathrm{C}}_{\Phi^{-}}\left(\mathrm{a}_{\mathrm{i}}\right)$ can be obtained.

Similarly to PROMETHEE II ranking, if an action has to be assigned to a single category, an assignment rule based on the net flows can be defined [15].

As a final note, there are some concerns that the DM should have when defining the reference profiles, such as two consecutive reference profiles must dominate each other; and the reference profile of a lower category is always "preferred" over the reference profile of a higher category due to the ordering of the categories from best to worst [15].

\subsubsection{ELECTRE TRI-B and ELECTRE TRI-C Methods Family}

The methods of the ELECTRE family are similar to those of the PROMETHEE family in what concerns the use of an outranking relation on the set of actions as a preference model. These methods are constructed as a result of concordance and non-discordance tests involving the DM preferences.

The ELECTRE TRI-B or the ELECTRE TRI-C use the concordance index concept, denoted $c\left(a, a^{\prime}\right)$, in which the DM must define the importance coefficients for each of the selected criteria. For that reason, a vector of importance coefficients denoted $\mathrm{w}_{\mathrm{j}}$, such that $\mathrm{w}_{\mathrm{j}}>0, \mathrm{j}=1, \ldots, \mathrm{n}$, is associated with the set of criteria. The concordance index is defined as follows [30]:

$$
c\left(a, a^{\prime}\right)=\sum_{j \in C\left(a P a a^{\prime}\right)} w_{j}+\sum_{j \in C\left(a Q a^{\prime}\right)} w_{j}+\sum_{j \in C\left(a I a^{\prime}\right)} w_{j}+\sum_{j \in C\left(a^{\prime} Q a\right)} w_{j} \cdot \varphi_{j}
$$

where

$$
\varphi_{j}=\frac{g_{j}(a)-g_{j}\left(a^{\prime}\right)+p_{j}}{p_{j}-q_{j}} \in[0,1]
$$

where $\varphi_{\mathrm{j}}$ represents how much the power of vote decreases according to the criteria $\mathrm{g}_{\mathrm{j}} \in \mathrm{C}\left(\mathrm{a}^{\prime} \mathrm{Qa}\right)$. 
A partial discordance index, denoted by $\mathrm{d}_{\mathrm{j}}\left(\mathrm{a}, \mathrm{a}^{\prime}\right)$, needs to be calculated, for which the DM may define veto thresholds for each one of the criteria, denoted $v_{j}$, such that $v_{j} \geq p_{j}$. The partial discordance index is defined as follows [30]:

$$
d_{j}\left(a, a^{\prime}\right)=\left\{\begin{array}{cl}
1 & \text { if } g_{j}(a)-g_{j}\left(a^{\prime}\right)<-v_{j}, \\
\frac{g_{j}(a)-g_{j}\left(a^{\prime}\right)+p_{j}}{p_{j}-v_{j}} & \text { if }-v_{j} \leq g_{j}(a)-g_{j}\left(a^{\prime}\right)<-p_{j} \\
0 & \text { if } g_{j}(a)-g_{j}\left(a^{\prime}\right) \geq-p_{j j}
\end{array}\right.
$$

Finally, the credibility of the comprehensive outranking, $\sigma\left(a, a^{\prime}\right)$, of a over $a^{\prime}$, reflects the strength of the statement "a outranks $\mathrm{a}^{\prime \prime \prime}$ (denoted $\mathrm{aSa}^{\prime}$ ) is defined as follows [30]:

$$
\sigma\left(a, a^{\prime}\right)=c\left(a, a^{\prime}\right) \prod_{j=1}^{n} T_{j}\left(a, a^{\prime}\right)
$$

where

$$
\mathrm{T}_{\mathrm{j}}\left(\mathrm{a}, \mathrm{a}^{\prime}\right)=\left\{\begin{array}{cc}
\frac{1-\mathrm{d}_{\mathrm{j}}\left(\mathrm{a}, \mathrm{a}^{\prime}\right)}{1-\mathrm{c}\left(\mathrm{a}, \mathrm{a}^{\prime}\right)} & \text { if } \mathrm{d}_{\mathrm{j}}\left(\mathrm{a}, \mathrm{a}^{\prime}\right)>\mathrm{c}\left(\mathrm{a}, \mathrm{a}^{\prime}\right) \\
1 & \text { otherwise }
\end{array}\right.
$$

A minimum degree of credibility, denoted $\lambda$, varying in the interval $[0.5 ; 1]$ needs to be defined by the DM. This parameter represents the DM beliefs on the statement "a outranks $\mathrm{a}^{\prime \prime \prime}$ taking all criteria into account. Accordingly, the binary relations associated with $\lambda$ are defined, as follows:

- $\quad \lambda$-outranking: $a S^{\lambda} \mathrm{a} \Leftrightarrow \sigma\left(\mathrm{a}, \mathrm{a}^{\prime}\right) \geq \lambda$

- $\quad \lambda$-preference: $\mathrm{aP}^{\lambda} \mathrm{a}^{\prime} \Leftrightarrow \sigma\left(\mathrm{a}, \mathrm{a}^{\prime}\right) \geq \lambda \wedge \sigma\left(\mathrm{a}^{\prime}, \mathrm{a}\right)<\lambda$

- $\quad \lambda$-indifference: $\mathrm{aI}^{\lambda} \mathrm{a}^{\prime} \Leftrightarrow \sigma\left(\mathrm{a}, \mathrm{a}^{\prime}\right) \geq \lambda \wedge \sigma\left(\mathrm{a}^{\prime}, \mathrm{a}\right) \geq \lambda$

- $\quad \lambda$-incomparability: $\mathrm{aR}^{\lambda} \mathrm{a}^{\prime} \Leftrightarrow \sigma\left(\mathrm{a}, \mathrm{a}^{\prime}\right)<\lambda \wedge \sigma\left(\mathrm{a}^{\prime}, \mathrm{a}\right)<\lambda$

The main difference between the ELECTRE TRI-B and ELECTRE TRI-C methods is the definition of the reference profiles. The first builds the outranking relation between actions and the limiting profiles of categories, while the last builds the outranking relation between actions and the central profile [14]. Hence, adapting the pseudo-criterion model to this particular case, the method allows evaluating the statement "action a is at least as good as the reference profile $\mathrm{r}^{\prime \prime}$.

In the case of ELECTRE TRI-C, which is the method applied in this article, the allocation of actions to the respective category is carried out through two distinct rules, called descending rule and ascending rule, but, in this case, they must be conjointly used. Each of these rules selects only one category for a possible assignment of an action.

These rules allow to highlight the highest category and lowest category, which seem potentially more suitable to receive the action. In this context, two situations can occur: the extreme categories coincide, which conveys confidence in the attribution, or they may diverge, which means that the attribution of such action remains ill-determined considering the characteristic actions selected initially to characterize each category.

\subsubsection{Eliciting Technical Parameters}

Eliciting preference information from the DM and formalizing it through technical parameters is a necessary task for most multicriteria methods. This fact is not only associated with the outranking approaches presented in the previous sections but also with all forms of preference modelling. Thus, sensitivity analyzes are crucial for validating the final results of a decision problem $[39,40]$. This is perhaps the most arduous and time-consuming task in the process of applying these methods.

Aware of these constraints, some authors, such as Mousseau, 1995; Bana e Costa and Vansnick, 1994; and Dias et al., 2002 [41-43], have developed preference elicitation techniques to help the analysts obtain information about the DM's preferences. 
An approach was developed from the dialogue between the analyst and the DM, which is called the direct approach. In these dialogues, the analyst tries to obtain specific information about the DM preferences. The success of this approach is strongly conditioned by several factors such as the DM willingness to actively participate in the process, the analyst's ability to guide the interactive process that allows facing cognitive limitation of the DM, the DM's difficulty in defining precise values for the preferred parameters, the possibility of considering inaccurate or uncertain data, the DM possible vague understanding of what the parameters represent and the possible evolution of their point of view during the elicitation process and finally in a decision involving more than one DM the lack of consensus can also be a critical issue [43].

However, in "repetitive" similar decisions, the direct approach may not be the best choice. This characteristic is exactly what happens in the WDN rehabilitation decisionmaking process due to the inevitable natural ageing process of infrastructure assets. It is believed that there will be a way to generalize this decision process including parameter elicitation. In these cases, disaggregation methods can be more useful [44]. Still, in this paper, the direct approach was used to measure the impact on the results of the methods.

\subsection{Affinity Propagation Clustering}

The process of identifying clusters in complex networks is fundamental to understanding the properties and structures of real-world networks [45]. Clustering is an efficient approach and aims at grouping similar data samples into clusters. The objective is to group data so that within the clusters the data is more similar than between clusters [45].

Affinity Propagation (AP) is an unsupervised learning technique for partitioning data into meaningful groups, developed in 2007 by Brendan Frey and Delbert Dueck [46]. This algorithm is based on the concept of "message passing" between data. For this, the AP algorithm considers all elements of the dataset to be studied as elected representatives of each cluster and exchanges messages iteratively between them until a good solution emerges [47]. There are advantages of using this algorithm, such as, not being necessary to define a priori the number of clusters, unlike other algorithms (e.g., k-means), and the center of the clusters being an element of the network itself when applied to WDN [45]. For more details, the authors suggest consulting Brendan Frey and Delbert Dueck (2007) [46].

The properties considered for the clustering process intend to capture the topological characteristics of the network and the process of the natural deterioration of the pipes, in this sense, the following properties are selected: the coordinates of the initial and final nodes of each pipe and the respective year of installation.

\section{Case Study}

The case study is a small WDN located in Portugal which has approximately $113 \mathrm{~km}$ of pipes with diameters ranging from 60 to $700 \mathrm{~mm}$, of different materials, predominantly asbestos cement $(67 \%)$ and PVC (33\%), mostly installed in the 1980 s or earlier. The WDN supplies c.a. $4.3 \mathrm{Mm}^{3}$ /year to 16,700 users.

The utility is in the process of carrying out a delegated management contract with the entity holding the infrastructure. For this, the utility must present a 15-year investment plan. Given the difficulties in determining which investments to make in the rehabilitation of the WDN, the present case study will help to define the investments by selecting the higher priority pipes to rehabilitate and allowing the establishment of an annual rehabilitation rate that enables a gradual renewal of the WDN, according to the utility's financial availability. The MCDA methodology developed by Carriço et al., 2021 [4], which defines rehabilitation investment priorities and financial budget to be annually allocated, is used for this purpose. 


\section{Methodology Application}

\subsection{Definition of the Assessment Criteria}

\subsubsection{Available Data and Criteria Establishment}

The process of establishing a coherent family of assessment criteria is a key step. The available data in the water utility limits the selection of possible assessment criteria. Due to the lack of human resources, technical and financial capacity, it is usually not possible for the water utilities to systematically generate the required information through daily routines [48]. Therefore, an attempt was made to select possible criteria considering the available data existing in the utility.

The utility had a hydraulic simulation model, developed in EPANET 2.2 [49], that was used to describe and simulate the hydraulic behavior of the system and to estimate the state variables for a $24 \mathrm{~h}$ period. This model was used to compute criteria regarding the pipes' hydraulic performance that rely on hydraulic parameters, such as pressure-head and velocity.

The analysis was carried out considering two different points of view-infrastructural integrity and hydraulic performance-taking advantage of the opportunity to change some diameters that have been demonstrated to be inadequate (excessively high or too small). Some problems were encountered when establishing the assessment criteria, as some criteria did not allow to distinguish the various pipes (e.g., minimum performance velocity, maximum performance velocity), thus these were discarded from the analysis. Through an iterative process between the analyst and the DM, seven criteria were established, though only some of these were used in the analysis.

\subsubsection{Remaining Useful Life}

The remaining useful life (RUL) of an asset corresponds to the period, at the date of the analysis, for which an asset is expected to adequately fulfill the function for which it was designed. The asset RUL corresponds to the ratio between the residual life (i.e., the amount of asset remaining life) and the expected useful life (i.e., the amount of time an asset is expected to be functional):

$$
\mathrm{RUL}_{\mathrm{i}}=\left[1-\left(\frac{\mathrm{Yr}_{\mathrm{j}}-\mathrm{Yr}_{\mathrm{i}, 0}}{\mathrm{tu} \mathrm{u}_{\mathrm{i}}}\right)\right] \times 100
$$

where $R_{U L}$ is the remaining useful life of asset $i, Y_{j}$ is the year of reference, $Y_{i, 0}$ is the year of installation of asset $i$, and $t u_{i}$ is the expected useful life $i$.

The excepted useful life depends on the type of asset and can be significantly affected by the quality of materials used, the transport and storage conditions, the installation conditions, adaptation to local conditions, and operation and maintenance practices [4]. In this case study, due to lack of reliable information, the excepted useful life of 50 years was considered for all pipes, regardless of the pipe material and diameter. The distribution of the pipes RUL is presented in Figure 2. Most pipes of the WDN have a RUL below 20\%, showing that these are reaching the end of their service life and need urgent replacement, in particular those made of asbestos cement. 


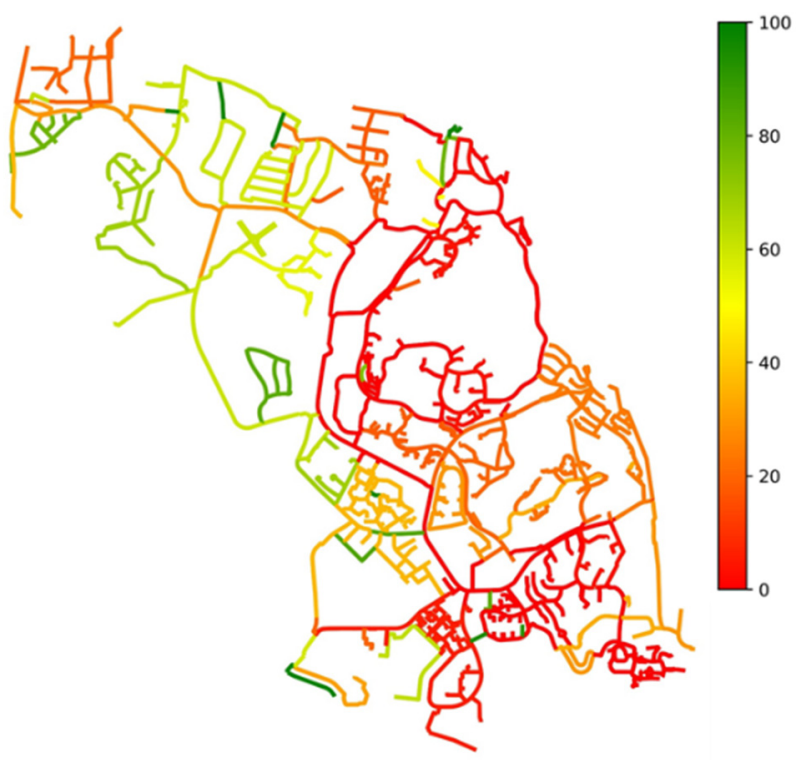

Figure 2. Obtained results for the criterion of remaining useful life.

\subsubsection{Minimum Velocity Performance Index}

This criterion allows assessing the hydraulic behavior of the flow in each pipe by comparing velocity with reference values, namely the minimum velocity $(0.3 \mathrm{~m} / \mathrm{s})$ and the maximum reference velocity, established by the Portuguese regulation (Decree-law 23/95). The minimum velocity in each of the pipes during a $24 \mathrm{~h}$ simulation was obtained by using the Python package called Water Network Tool for Resilience (WNTR) [50]. This value is converted into a performance index by applying the penalty function depicted in Figure 3 , as proposed by Coelho (1997) and Coelho and Alegre (1999) [51,52].

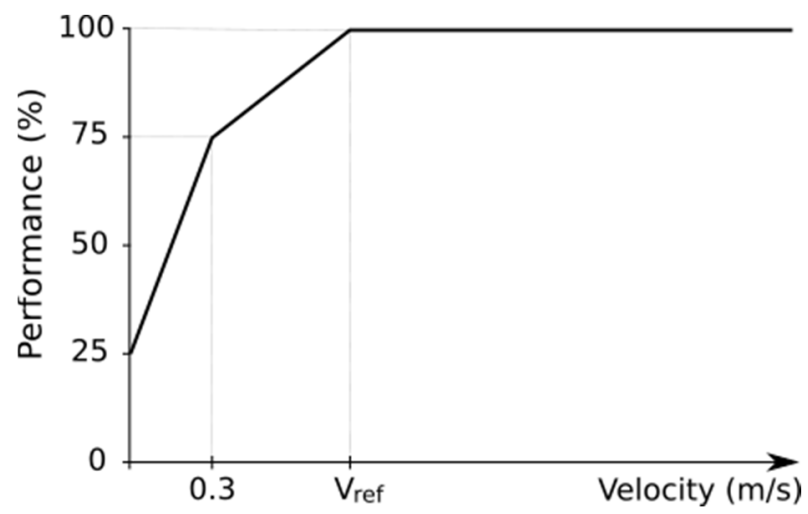

Figure 3. Minimum performance velocity function.

The main purpose for defining this criterion is the possibility of easily inferring possible problems related to water quality. Usually, low velocities are an indicator of high residence times and water quality problems (e.g., high chlorine decay, disinfection by-products formation, microbiological regrowth) since biological and chemical reactions depend on time [53].

Figure 4 depicts the results obtained for the criterion of the minimum velocity performance index. These results show that, in general, the pipes present a performance of less than $50 \%$. This fact is due to the over-size of the pipes, which need to have a minimum diameter of $90 \mathrm{~mm}$ to take into account an eventual emergency situation (e.g., fire situation), according to the Portuguese regulation. Since there are minor differences in the pipe's performance and this index does not allow them to be distinguished. This criterion was 
discarded from the analysis. In other cases where a large variation of this index is observed, this index should be included in the MCDA.

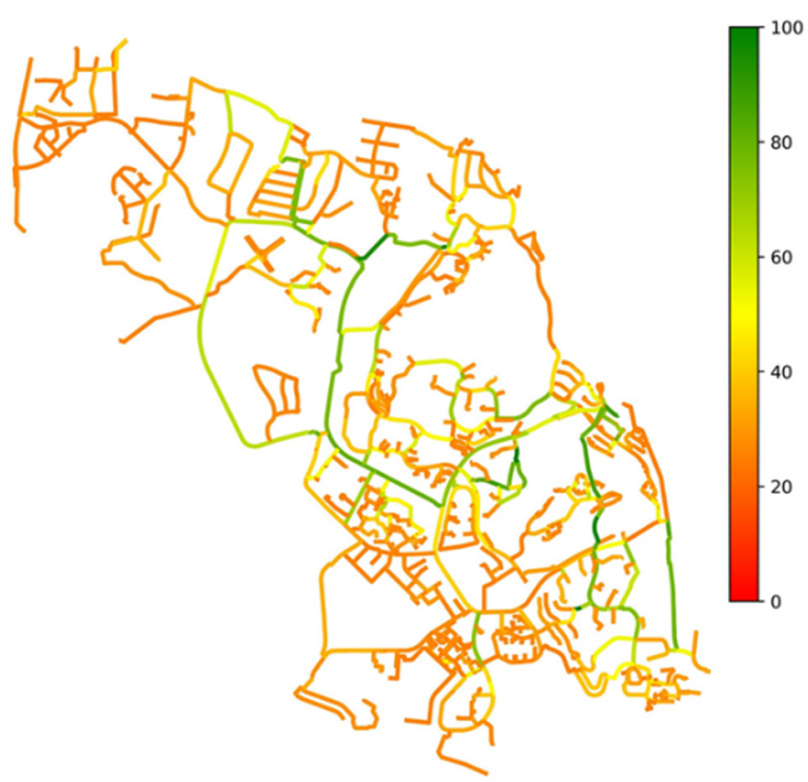

Figure 4. Obtained results for the criterion of minimum performance velocity index.

\subsubsection{Maximum Velocity Performance Index}

This is a performance index using a penalty function that assesses the state variable related to the maximum velocity in each of the pipes by comparing it to reference values. This index allows us to identify pipes with high friction losses associated with high velocities that cause unnecessary energy dissipation.

According to the Portuguese regulation, the maximum reference velocity in the distribution pipes for the peak flow should not exceed the following value:

$$
\mathrm{V}_{\text {ref }}=0.127 \mathrm{D}^{0.4}
$$

where $V_{\text {ref }}$ is the maximum reference velocity $(\mathrm{m} / \mathrm{s})$ and $\mathrm{D}$ is the pipe inner diameter $(\mathrm{mm})$.

Figure 5 presents the maximum velocity penalty function. Figure 6 shows the results obtained for this index for each pipe of the WDN. Most pipes present a good maximum velocity performance, higher than 0.80 . As with the previous index, this index is also not adequate to distinguish the pipes between each other; therefore, it was discarded from the analysis.

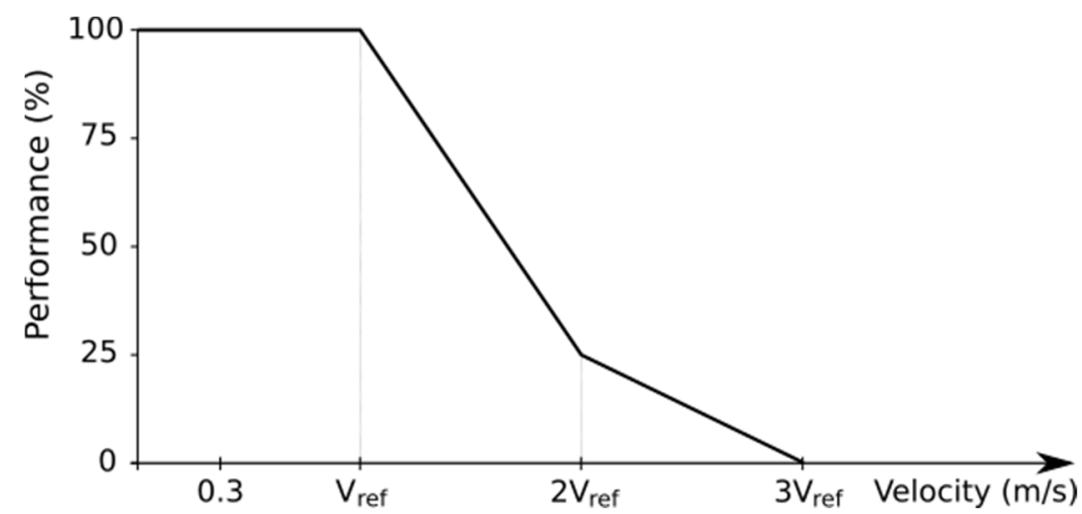

Figure 5. Maximum performance velocity function. 


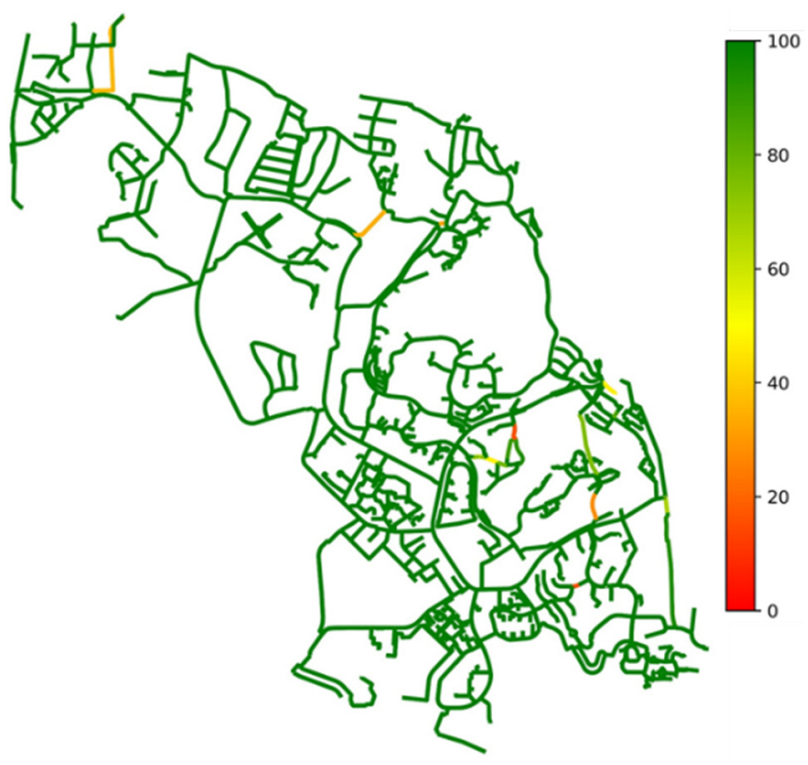

Figure 6. Obtained results for the criterion of maximum performance velocity index.

\subsubsection{Number of Pipe Bursts in the Last 10 Years}

Typically, the pipe burst rate is an assessment metric in pipe rehabilitation prioritization. Although the literature suggests the use of long historical data records [54] to compute the burst rate, the water utility has an extensive history of georeferenced data related to the burst of pipes for the last 10 years. Thus, instead of the annual burst rate, the total number of pipe bursts that occurred in the last 10 years were used in the analysis.

Figure 7 depicts the results obtained for the number of pipe bursts in the last 10 years. Most pipes in the WDN have had very few pipe bursts in the last 10 years.

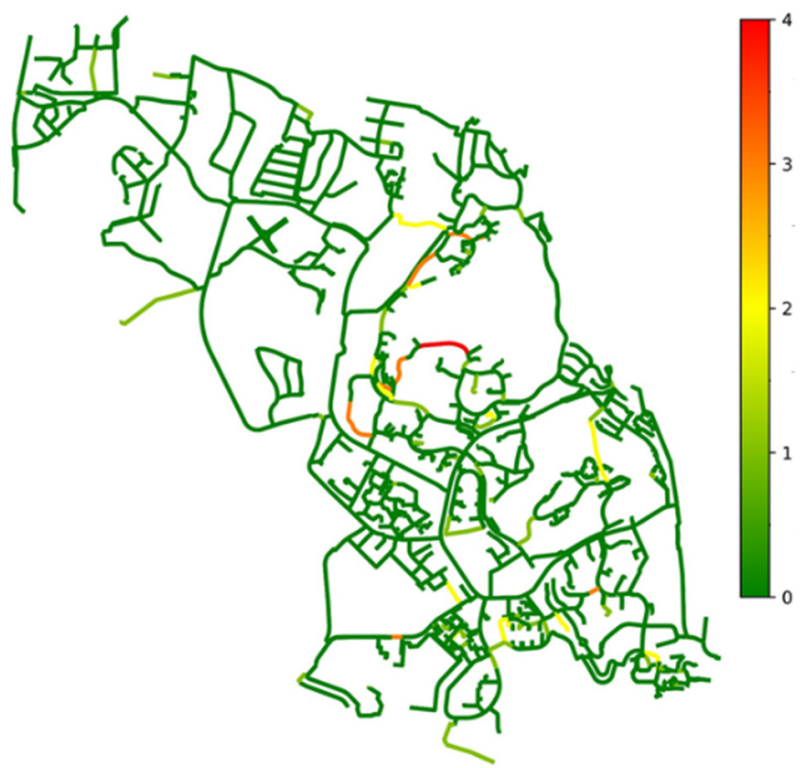

Figure 7. Obtained results for the criterion of the number of pipe bursts in the last 10 years.

\subsubsection{Consumption Satisfaction in Case of Water Service Disruption}

This criterion allows assessing the consequences to the system caused by a pipe failure of the WDN. A failure is a service disruption due to a pipe burst.

Most hydraulic simulation models are demand-driven, that is demand is set at the nodes and pressure heads are computed accordingly. However, in real conditions, the nodal demand is not fixed and is strongly related to the nodal pressure, commonly called pressure- 
driven demand. Different relations have been suggested between nodal demand and pressure, but the equation presented by Wagner et al., 1988 [55] has been recognized as the most appropriate.

Therefore, another model known as the pressure-driven model is used to take this fact into account and to allow a more realistic simulation of the WDN hydraulic behavior. Therefore, the fixed nodal demand in the continuity equation was replaced by the equation proposed by Wagner et al., 1988 [55] as described below:

$$
\begin{array}{ll}
\mathrm{Q}_{\mathrm{i}}^{\mathrm{av}}=\mathrm{Q}_{\mathrm{i}}^{\mathrm{rq}} & \mathrm{H}_{\mathrm{i}} \geq \mathrm{H}_{\mathrm{i}}^{\text {des }} \\
\mathrm{Q}_{\mathrm{i}}^{\mathrm{av}}=\mathrm{Q}_{\mathrm{i}}^{\mathrm{rq}}\left(\frac{\mathrm{H}_{\mathrm{i}}-\mathrm{H}_{\mathrm{i}}^{\text {min }}}{\mathrm{H}_{\mathrm{i}}^{\mathrm{qq}}-\mathrm{H}_{\mathrm{i}}^{\text {min }}}\right)^{\left(\frac{1}{n}\right)} & \mathrm{H}_{\mathrm{i}}^{\text {min }}<\mathrm{H}_{\mathrm{i}}<\mathrm{H}_{\mathrm{i}}^{\text {des }} \\
\mathrm{Q}_{\mathrm{i}}^{\mathrm{av}}=0 & \mathrm{H}_{\mathrm{i}} \leq \mathrm{H}_{\mathrm{i}}^{\text {min }}
\end{array}
$$

where $Q_{i}^{r q}$ is the required demand at the node $i, Q_{i}^{a v}$ is the available demand at node $i$, $\mathrm{H}_{\mathrm{i}}$ is the available head at node $\mathrm{i}, \mathrm{H}_{\mathrm{i}}^{\mathrm{rq}}$ is the minimum required pressure-head or design pressure-head, $\mathrm{H}_{\mathrm{i}}^{\mathrm{min}}$ is the minimum pressure-head and $\mathrm{n}$ is the head exponent varying between 0.5 and 2 .

There is no demand at the node if the head is less than $\mathrm{H}_{\mathrm{i}}^{\min }$. The required demand is fully met when the head is more than $\mathrm{H}_{\mathrm{i}}^{\mathrm{rq}}$. For a pressure-head between $\mathrm{H}_{\mathrm{i}}^{\mathrm{min}}$ and $\mathrm{H}_{\mathrm{i}}^{\mathrm{rq}}$, the demand is interpolated from zero to the required demand.

Accordingly, for a given interruption scenario due to pipe failure $j$, the demand satisfaction rate defined by Creaco and Franchini, 2012 [56] is adopted to measure the importance of the component for consumption fulfillment, as follows:

$$
S_{j}=\frac{\sum_{i=1}^{n} Q_{i, j}^{a v}}{\sum_{i=1}^{n} Q_{i}^{r q}}
$$

where $S_{j}$ is the demand satisfaction rate, $n$ is the number of nodes in the hydraulic model and $Q_{i, j}^{a v}$ is the quantity supplied to users at node $i$ as a function of nodal demand $Q_{i}^{r q}$ is calculated based on the pressure-driven simulation applied to the $j$-th failure scenario.

Figure 8 depicts the results obtained for the criterion of consumption satisfaction in the case of water service disruption. The obtained results show that the WDN has high redundancy and, therefore, most of the pipes have a value of $100 \%$. This means that in the case of pipe failure, the nodal demand $\mathrm{Q}_{\mathrm{i}}^{\mathrm{rq}}$ is fully satisfied.

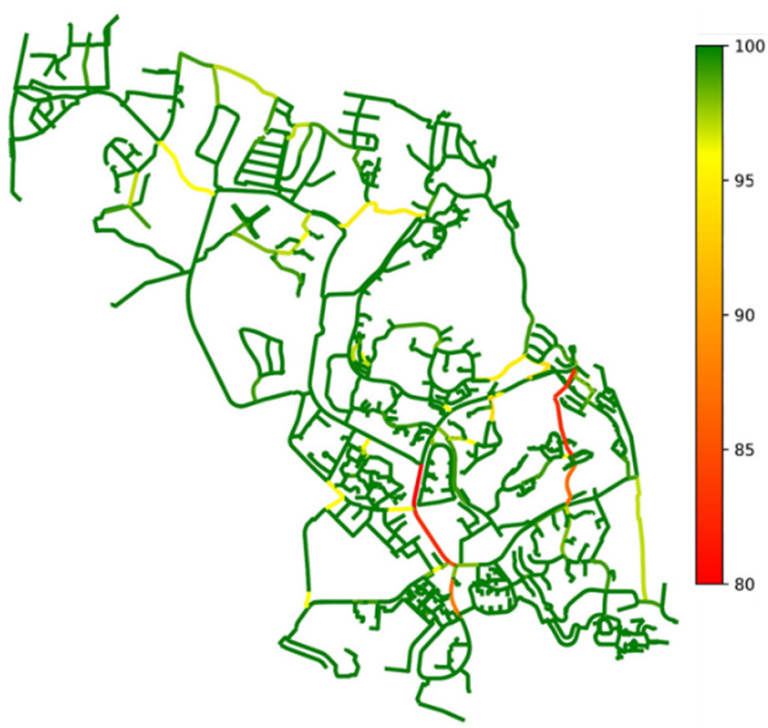

Figure 8. Obtained results for the criterion of consumption satisfaction in case of water service disruption. 


\subsubsection{Pipe Material}

Asbestos cement $(\mathrm{AC})$ is a pipe material that is no longer used, since the asbestos fibers are carcinogenic when inhaled. However, no evidence is presented regarding the risk to human health of this material in contact with water. The operators when handling these pipes in case of a failure repair are subjected to considerable exposure of this risk. Due to the natural ageing process, these pipes show frequent bursts requiring necessary repairs. As a result, the DM suggests the integration of a criterion that penalizes the pipes made of asbestos cement, so that they are gradually replaced by pipes made of other, more modern materials (e.g., HDPE).

A criterion was defined through a codification that represents the pipe material associated with one of three classes ordered from 1 to 3 . As the purpose is only to penalize the pipes in AC, they were assigned to Class 1 (red) and the rest of the pipes to Class 3 (green). Class 2 is just a dummy class needed to apply the aggregation methods. No pipes have been assigned to this class. Figure 9 depicts the results obtained for the criterion of pipe material. Most WDN pipes are made of AC, which meets DM concerns.

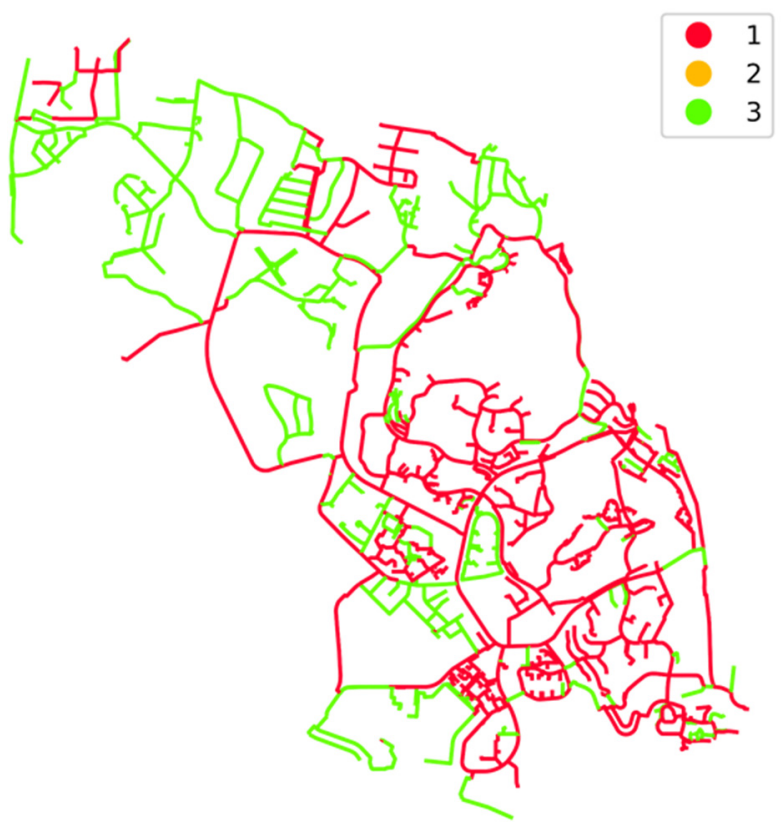

Figure 9. Obtained results for the criterion of pipe material.

\subsubsection{Maximum Pressure-Head Levels}

The criterion of pressure levels is considered due to the difficulty in identifying the pipes with higher leakage rates, since leakage is proportional to pressure, and also leaky pipes tend to exist in higher pressure zones [57]. Accordingly, the DM decided to consider in the analysis a criterion that, with the existing data, would allow inferring which pipes are likely to have more leaks.

Figure 10 depicts the results obtained for the criterion of maximum pressure-head levels. The WDN has several areas with very high pressure-head values (between 50 and $60 \mathrm{~m}$ ), located in the lowest elevation zones. If there are leaks due to structural problems (e.g., deteriorated joints, cracks), the volume of water lost will be higher when compared to areas subject to lower pressures; thus, these areas are a rehabilitation priority. 


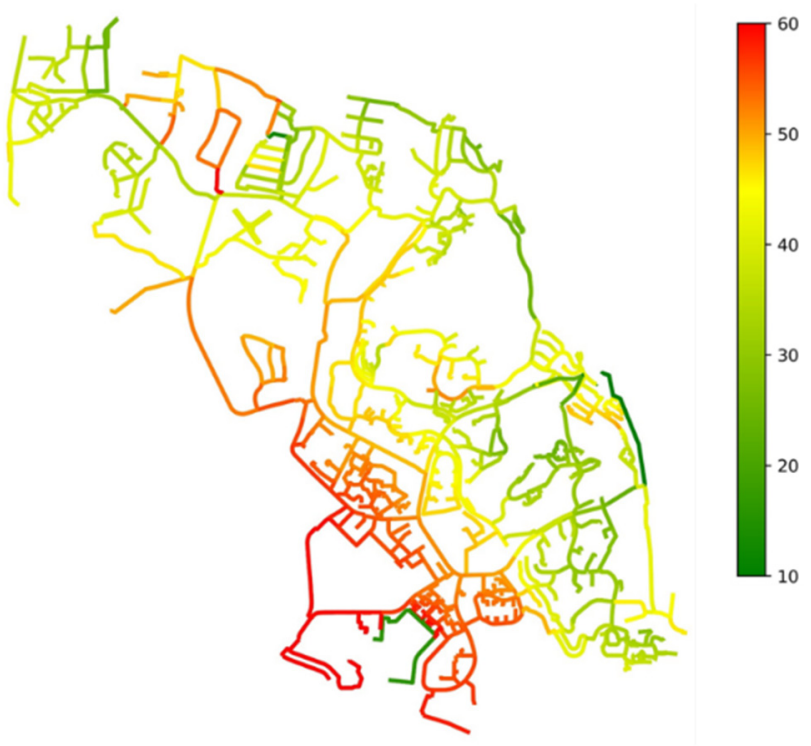

Figure 10. Obtained results for the criterion of maximum pressure-head levels.

\subsection{Selection of the Assessment Criteria}

The application of the aggregation method requires a fundamental condition, which is selecting the criteria that allow distinguishing the pipes. Since some of the criteria defined above did not allow distinguishing pipes in the decision-making process (i.e., defining priorities of pipe rehabilitation interventions), those have been eliminated, namely Minimum velocity performance index and Maximum velocity performance index. The awareness that these criteria did not allow the distinction between pipe performances was reached during the interactive process between the analyst and the DM, where the aggregation methods were applied and the results were subsequently assessed.

Therefore, the following five assessment criteria are used in the analysis: Remaining useful life (C1), Number of pipes burst in the last 10 years (C2), Pipe material (C3), Consumption satisfaction in case of water service disruption (C4) and Maximum pressure-head levels (C5).

\subsection{Application of the Aggregation Methods and Sensitivity Analysis}

The authors expected, since the beginning, that the application of the two methods would result in identical outcomes. Therefore, the same parameters in the two methods were considered to allow the results to be compared. Table 2 presents a summary of the parameters considered for both methods.

Table 2. Central profiles and preference discrimination thresholds.

\begin{tabular}{cccccc}
\hline Parameter & C1 & C2 & C3 & C4 & C5 \\
\hline $\mathrm{g}\left(\mathrm{cp}_{1}\right)$ & 0 & 2 & 1 & 95 & 60 \\
$\mathrm{~g}\left(\mathrm{cp}_{2}\right)$ & 20 & 1 & 2 & 98 & 40 \\
$\mathrm{~g}\left(\mathrm{cp}_{3}\right)$ & 50 & 0 & 3 & 100 & 30 \\
$\mathrm{q}$ & 5 & 0 & 0 & 0 & 5 \\
$\mathrm{p}$ & 10 & 0 & 0 & 0 & 10 \\
Preference direction & Max & Min & Max & Max & Min \\
\hline
\end{tabular}

Legend: $p$-preference threshold on each criterion; $q$-indifference threshold on each $c r i t e r i o n ; ~ g\left(c p_{i}\right)-$ performance of central profile on each criterion.

The results obtained through the application of the methods must convey a degree of credibility that allows a convinced and secure decision-making process. Therefore, carrying out sensitivity analyses, by varying the importance coefficients by defining various preference scenarios, is essential in this process. 
Briefly, in a scenario where a small variation of a single parameter results in a complete change in the sorting, it indicates an unstable solution. Thus, the DM must be aware that the conclusions drawn are valid only for that precise set of chosen parameters and any small error or perturbation leads to a very different solution. On the other hand, if the sorting remains the same for a wide range of different sets of parameters, then the DM can be quite confident in the stability of the solution. Therefore, a sensitivity analysis was carried out for each method.

Considering the high number of pipes considered in the assessment, it is expected that a small variation in the parameters can lead to changes in the results, even if small. As a consequence, in order to be able to carry out an effective sensitivity analysis, the DM was asked to identify considerable changes in the results through visual validation. Therefrom, three variation scenarios were defined for the importance coefficients. Table 3 shows the established variation scenarios.

Table 3. Importance coefficients to sensitivity analysis.

\begin{tabular}{llllll}
\hline Scenarios & C1 & C2 & C3 & C4 & C5 \\
\hline Scenario 1 & 20 & 20 & 20 & 20 & 20 \\
Scenario 2 & 30 & 20 & 30 & 10 & 10 \\
Scenario 3 & 40 & 10 & 40 & 5 & 5 \\
\hline
\end{tabular}

\subsubsection{ELECTRE TRI-C}

Considering the parameters presented in Table 2 and the scenarios established in Table 3, the results obtained with the application of ELECTRE TRI-C (central profiles) are presented in Figure 11. These results show differences between the application of scenario 1 and the other two defined scenarios. This demonstrates that by varying the importance coefficients, the sensitivity analysis presents different results. Even so, it is possible to conclude that there is a significant amount of pipes that are attributed to the high priority category, independently of the considered scenario. This fact gives the DM confidence in the decision to rehabilitate these pipes. Another important finding is that a large extent of the WDN needs urgent rehabilitation, which is in line with the initial notion of the DM.

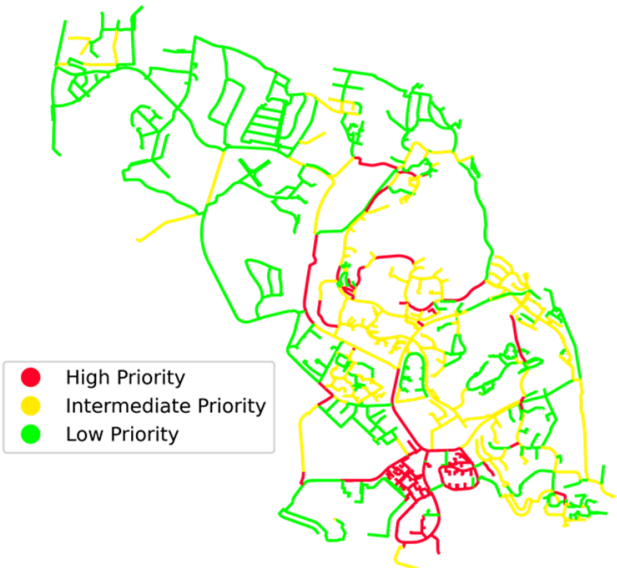

(a)

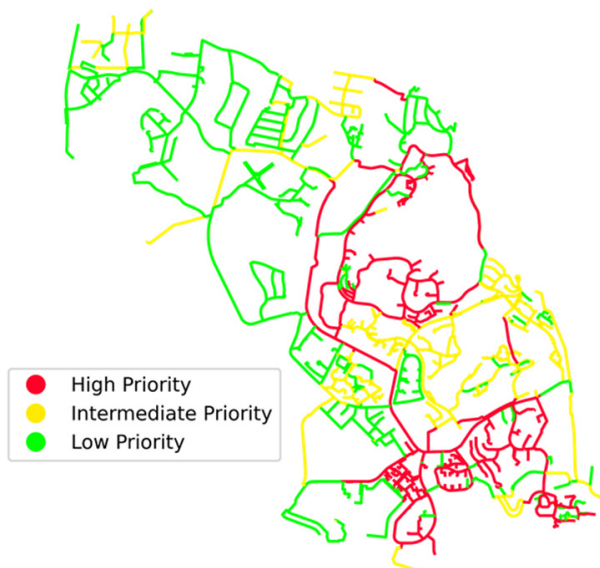

(b)

Figure 11. Cont. 


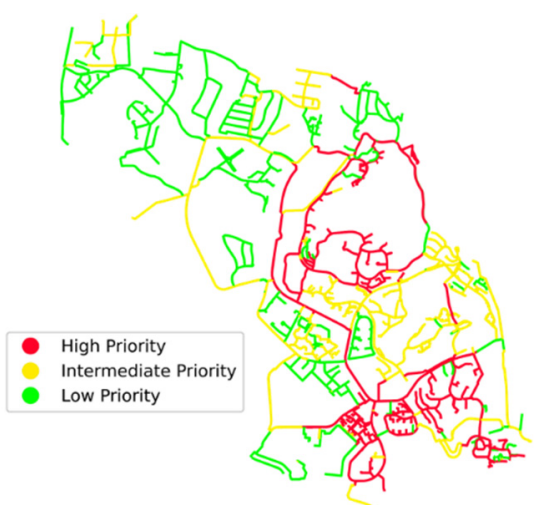

(c)

Figure 11. Plot of ELECTRE TRI-C results: (a) Scenario 1; (b) Scenario 2; (c) Scenario 3.

\subsubsection{FlowSort (Central Profiles)}

The same process was repeated by applying the FlowSort method also for the central profiles so that it was possible to compare it with the previous method. The obtained results are presented in Figure 12. The obtained results demonstrate that most pipes are of an intermediate rehabilitation priority with very few exceptions. Even so, with the performance of a sensitivity analysis varying the importance coefficients, the differentiation between categories increases. This is noticed when comparing the results of Scenarios 1 and 3.

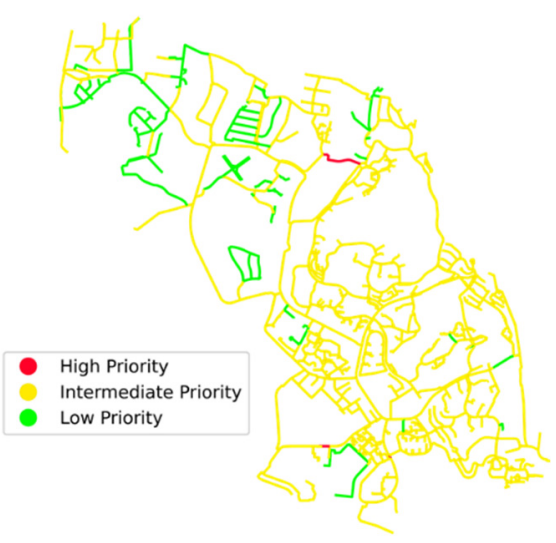

(a)

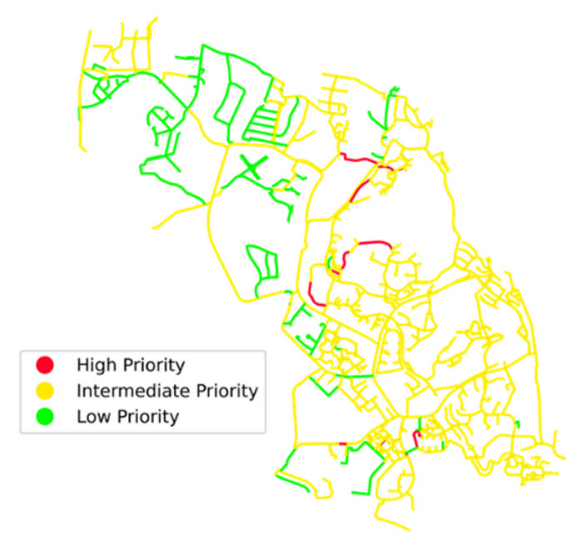

(b)

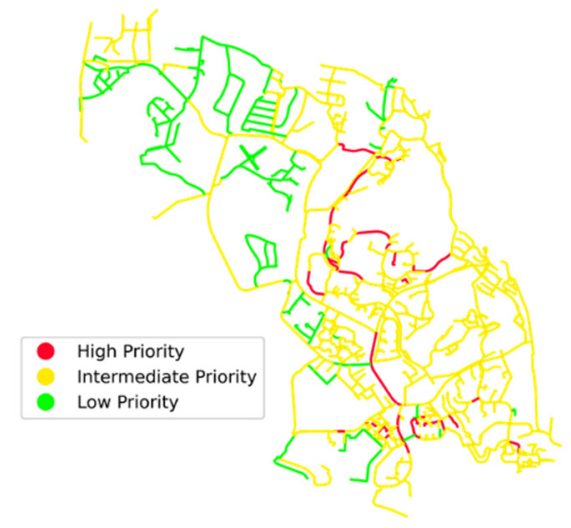

(c)

Figure 12. Plot of FlowSort results: (a) Scenario 1; (b) Scenario 2; (c) Scenario 3. 
Some inability of the FlowSort method applied to the specific WDN rehabilitation problem to differentiate the pipes in relation to priority categories is identified. Note that the structuring and evaluating of the problem are largely dependent on the available data. Therefore, it is not possible to conclude that the method should not be applied to this problem, but that, according to the existing data, it is not possible to differentiate the pipes by priority categories.

\subsection{Elaboration of Final Recommendations}

The final recommendations should translate the formal language of the MCDA into a simpler, more understandable narrative for the DM. The decision-making process in the utilities is carried out not by engineers, but by managers who need to allocate funds in investment plans for the rehabilitation of WDN.

This fact makes it essential to contribute to the definition of an annual budget that allows for a gradual and continuous renewal of the WDN. Therefore, meetings were held between the engineering teams and the DM where a standard for the rehabilitation process was defined, hence facilitating stock management as well as the attribution of a rehabilitation cost to each pipe.

Briefly, the rehabilitation was carried out by replacing the existing pipes for pipes with an equivalent diameter, called like-for-like rehabilitation. Pipes with diameters larger than $300 \mathrm{~mm}$ will be replaced by pipes of ductile iron (DI) material and the rest by high-density polyethylene (HDPE). By defining this rule, it was possible to make a budget estimate of the rehabilitation needs for the results obtained for each method, scenario, and category, as shown in Table 4.

Table 4. Investment costs.

\begin{tabular}{ccccc}
\hline \multirow{2}{*}{ Method } & Scenarios & $\begin{array}{c}\text { High Priority } \\
(\boldsymbol{(})\end{array}$ & $\begin{array}{c}\text { Intermediate } \\
\text { Priority (€) }\end{array}$ & Low Priority (€) \\
\hline \multirow{2}{*}{ ELECTRE TRI-C } & Scenario 1 & $1.96 \mathrm{M}$ & $3.42 \mathrm{M}$ & $5.59 \mathrm{M}$ \\
& Scenario 2 & $3.46 \mathrm{M}$ & $3.34 \mathrm{M}$ & $4.17 \mathrm{M}$ \\
& Scenario 3 & $3.46 \mathrm{M}$ & $4.30 \mathrm{M}$ & $3.22 \mathrm{M}$ \\
FlowSort & Scenario 1 & $38 \mathrm{k}$ & $9.73 \mathrm{M}$ & $1.20 \mathrm{M}$ \\
& Scenario 2 & $179 \mathrm{k}$ & $9.03 \mathrm{M}$ & $1.77 \mathrm{M}$ \\
& Scenario 3 & $698 \mathrm{k}$ & $8.47 \mathrm{M}$ & $1.80 \mathrm{M}$ \\
\hline
\end{tabular}

A significant variation of total budgets is observed in both methods depending on the considered scenario, which has relevant consequences on the budget amount to be allocated for rehabilitation in subsequent years.

Since the decision process is iterative, the DM was asked to assess the results together with the engineering team and to select the result that approached the expectations. At this stage of the process, a consensus was found regarding the best solution; thus, the method ELECTRE TRI-C was selected with Scenario 2. According to the financial availability, it is feasible to allocate an average of $231 \mathrm{k} €$ /year in the rehabilitation of the WDN over 15 years. As a result, the utility will present an annual pipe rehabilitation rate of approximately $2 \%$. This value is suggested by the Portuguese water and wastewater regulator, as a reference value [58].

Figure 13 depicts the number of times each pipe was assigned to the high priority category by the six developed decision models. This analysis allows the decision-making process regarding the selection of priority pipes to be carried out in a more robust and well-founded manner. 


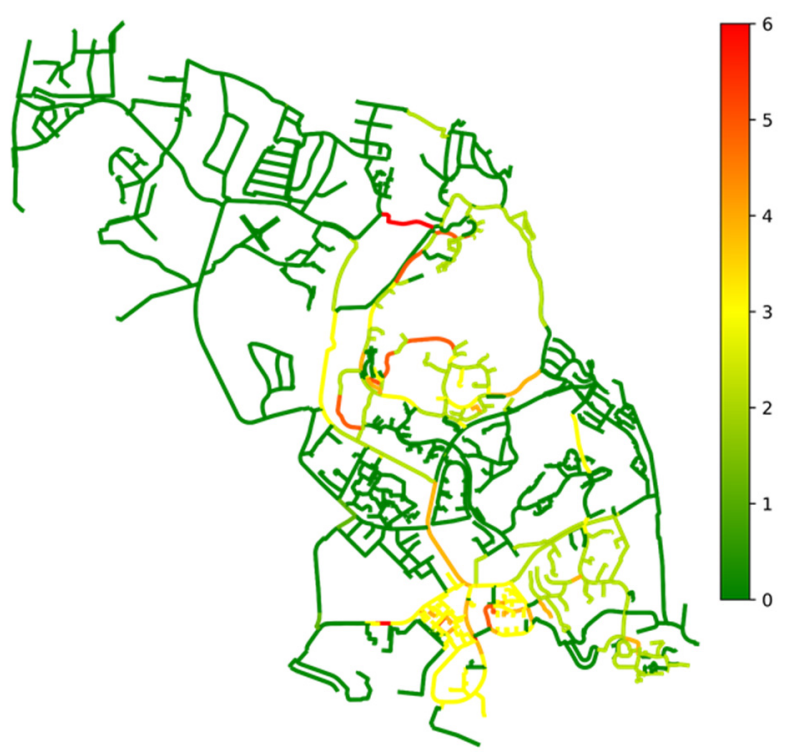

Figure 13. Frequency of attribution of pipes to the category of high rehabilitation priority.

\subsection{Affinity Propagation Clustering}

The Carriço et al., 2021 [4] methodology implies that the estimation and planning of investment needs are carried out on the basis of individual pipes. However, this approach is not consistent with actual replacement actions at water utilities, as replacement works include a set of neighboring pipes located in the same street or area, called herein rehabilitation units. To take this fact into account, the unsupervised learning technique Affinity Propagation (AP) was applied. The used dataset consisted of the pipes assigned to the high priority category resulting from the application of the ELECTRE TRI-C and Scenario 2. Once the set of pipes to be considered was defined, the most relevant properties to be considered for the formation of clusters were established. Thus, the properties considered were the coordinates of the start and end nodes of each pipe and the respective year of installation. Figure 14 illustrates the results of applying the AP with the indication of the 14 identified clusters within the high priority pipes (black pipes were not considered in this analysis). Clusters represent rehabilitation units.

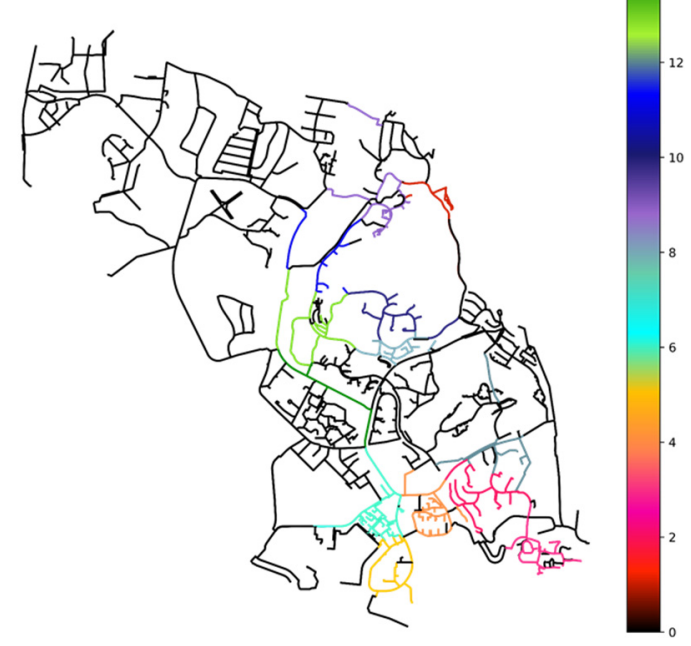

Figure 14. Clusters formed by Affinity propagation.

The obtained results show the definition of 14 clusters representing, on average, an extension of $2.1 \%$ of the WDN extension per cluster. It is important to remember again 
that this value is within the range suggested by the Portuguese regulator as an adequate percentage of annual rehabilitation. The investment plan has a 15-year horizon, which implies that the DM should carry out the rehabilitation of one cluster per year. Table 5 demonstrates the WDN extension associated with each cluster and the respective costs. Note that the AP cluster technique does not allow a consideration of the number of clusters a priori. If the methodology results in a number of clusters higher than the time horizon of the investment plan, the decision-making process should annually consider the rehabilitation of more than one cluster.

Table 5. Percentage of WDN extension and respective costs of each cluster.

\begin{tabular}{ccc}
\hline Cluster ID & Percentage of WDN Length (\%) & Cost (k€) \\
\hline 1 & 1.5 & 108 \\
2 & 2.8 & 184 \\
3 & 2.3 & 143 \\
4 & 2.7 & 191 \\
5 & 2.0 & 255 \\
6 & 3.5 & 604 \\
7 & 0.2 & 17 \\
8 & 1.6 & 111 \\
9 & 2.4 & 154 \\
10 & 2.1 & 133 \\
11 & 1.6 & 364 \\
12 & 2.4 & 167 \\
13 & 2.7 & 511 \\
14 & 1.3 & 520 \\
\hline
\end{tabular}

This section proposes to explore a technique for defining rehabilitation units that are more in line with the rehabilitation actions practised by water utilities. Still, the authors denote the importance of carrying out further research in this area.

\section{Results Discussion}

The application of the two methods to the entire WDN showed that small variations in the DM preferences lead to different results that are difficult to assess. This finding may indicate that there is an acceptable maximum number of actions to consider (i.e., number of pipes to be assessed). This condition resulted in all analyses of the results being performed with less precision.

Considering the extension of the WDN that needs urgent rehabilitation, values between 1.96-3.46 M€ were obtained for the ELECTRE TRI-C method and 38-698 k€ for the FlowSort method. Apparently, the ELECTRE TRI-C method allows for greater differentiation of pipes between the various pre-defined priority categories. This factor made the ELECTRE TRI-C method more acceptable and reliable from the perspective of DM. Note that decision-making is the responsibility of the DM, so it is essential to have strong confidence in the decision being taken.

It is possible to divide the problem into two distinct aspects: the definition of an annual budget for the rehabilitation of pipes and the selection of specific pipes that need rehabilitation. Hence, the application of the ELECTRE TRI-C method proved to be effective in estimating the rehabilitation budgets, but was not sufficiently precise to define the pipes to be rehabilitated. The DM disbelief in the selection of specific pipes that need rehabilitation is justified by the methodology applied based on individual pipes.

This approach is not consistent with the actual replacement projects undertaken annually by water utilities, as they carry out replacement works incoherent sets of neighboring pipes. A cluster analysis of the pipes assigned to the high priority category considering the topological properties and the date of installation of the pipes added to the existing methodology is a good solution to delimit the rehabilitation units and quantify the associated costs. Additionally, this allows the planning to be carried out in phases over 15 years. It is 
possible to conclude with the application of the AP that although on average the extent to be rehabilitated is approximately $2.1 \%$, the associated costs have a considerable dispersion varying between 17-604 k€ per rehabilitation unit. Therefore, the DM will have to make a greater financial effort to rehabilitate some rehabilitation units.

\section{Conclusions}

The difficulties in selecting priority pipes for rehabilitation and to establish their respective budgets is a daily reality faced by many water utility managers. MCDA techniques can be very useful in these cases. The current paper demonstrates and discusses the application of two MCDA techniques to classify the pipes of a real WDN into three priority categories. Three distinct scenarios were defined to represent the preferences of the DM. The used methods were ELECTRE TRI-C and FlowSort (central profiles). Both methods give very different results. The FlowSort method presented higher extensions of WDN to be rehabilitated. Therefore, the ELECTRE TRI-C proved to be more effective.

The authors believe that there are more suitable methods than others to solve the specific problem of selecting pipes to be rehabilitated and the respective budgets to make the rehabilitation process viable from a long-term perspective.

These approaches imply that the planning of investment needs is carried out based on individual pipes, but these approaches are not consistent with the actual rehabilitation projects. A clustering technique called Affinity propagation, together with cost functions, were applied to define and quantify homogeneous rehabilitation units. Even so, the methodology did not prove to be rigorous enough for the selection of pipes to be rehabilitated. On the other hand, it proved effective to estimate annual budgets for rehabilitation.

Despite the contribution to the extension of the existing methodology, the authors still note the need for further research into techniques for delimiting rehabilitation units. Therefore, future research will focus on the development of a clustering method that considers the topology and the natural ageing process of the WDN and the effect of the rehabilitation of these clusters on the quality of service provided to users, in order to integrate a more holistic MCDA methodology.

Author Contributions: Conceptualization, J.C., N.C. and D.C.; methodology, J.C., N.C. and D.C.; formal analysis, J.C.; writing-original draft preparation, J.C.; writing-review and editing, N.C. and D.C.; supervision, N.C. and D.C.; project administration, N.C.; funding acquisition, N.C. All authors have read and agreed to the published version of the manuscript.

Funding: This research and the APC were funded by the Fundação para a Ciência e Tecnologia (FCT) through the WISDom project, grant number No. DSAIPA/DS/0089/2018.

Institutional Review Board Statement: Not applicable.

Informed Consent Statement: Not applicable.

Data Availability Statement: The data presented in this study are available on request from the corresponding author.

Acknowledgments: The authors would like to thank the FCT for funding this research through the WISDom project (grant number DSAIPA/DS/0089/2018) and the water utility for providing data from the case study.

Conflicts of Interest: The authors declare no conflict of interest. The funders had no role in the design of the study; in the collection, analyses, or interpretation of data; in the writing of the manuscript, or in the decision to publish the results.

\section{References}

1. Clark, R.M.; Sivaganesan, M.; Selvakumar, A.; Sethi, V. Cost Models for Water Supply Distribution Systems. J. Water Resour. Plan. Manag. 2002, 128, 312-321. [CrossRef]

2. Selvakumar, A.; Tafuri, A.N. Rehabilitation of Aging Water Infrastructure Systems: Key Challenges and Issues. J. Infrastruct. Syst. 2012, 18, 202-209. [CrossRef] 
3. Amaral, R.; Alegre, H.; Matos, J.S. Highlights of key international water infrastructure asset management initiatives, and trends, challenges and developments in Portugal. Water Policy 2017, 19, 128-146. [CrossRef]

4. Carriço, N.; Covas, D.; Almeida, C. Multi-criteria decision analysis in urban water asset management. Urban Water J. 2021, 18, 558-569. [CrossRef]

5. Bello, O.; Abu-Mahfouz, A.M.; Hamam, Y.; Page, P.R.; Adedeji, K.B.; Piller, O. Solving management problems in water distribution networks: A survey of approaches and mathematical models. Water 2019, 11, 562. [CrossRef]

6. Scholten, L. Multi-Criteria Decision Analysis for Water Supply Infrastructure Planning under Uncertainty. Ph.D. Thesis, ETH Zurich, Zurich, Switzerland, 2013.

7. Covas, D.; Cabral, M.; Pinheiro, A.; Marchionni, V.; Antunes, S.; Lopes, N.; Mamouros, L.; Brôco, N. Custos de Construção de Infraestruturas Associadas ao Ciclo Urbano da Água; ERSAR: Lisbon, Portugal, 2018; pp. 133-142. ISBN 978-972-98996-4-5.

8. Wang, J.J.; Jing, Y.Y.; Zhang, C.F.; Zhao, J.H. Review on multi-criteria decision analysis aid in sustainable energy decision-making Renew. Sustain. Energy Rev. 2009, 13, 2263-2278. [CrossRef]

9. Roy, B. Paradigms and Challenges. In Multiple Criteria Decision Analysis: State of the Art Surveys; Figueira, J., Greco, S., Ehrgott, M., Eds.; Springer: Berlin/Heidelberg, Germany, 2005; pp. 3-24. ISBN 0-387-23081-5.

10. Baur, R.; Le Gauffre, P.; Sægrov, S. Multi-criteria decision support for annual rehabilitation programmes in drinking water networks. Water Sci. Technol. Water Supply 2003, 3, 43-50. [CrossRef]

11. Choi, T.; Han, J.; Koo, J. Decision method for rehabilitation priority of water distribution system using ELECTRE method. Desalin. Water Treat. 2015, 53, 2369-2377. [CrossRef]

12. Scholten, L.; Scheidegger, A.; Reichert, P.; Mauer, M.; Lienert, J. Strategic rehabilitation planning of piped water networks using multi-criteria decision analysis. Water Res. 2014, 49, 124-143. [CrossRef]

13. Tscheikner-Gratl, F.; Egger, P.; Rauch, W.; Kleidorfer, M. Comparison of multi-criteria decision support methods for integrated rehabilitation prioritization. Water 2017, 9, 68. [CrossRef]

14. Almeida-Dias, J.; Figueira, J.R.; Roy, B. Electre Tri-C: A multiple criteria sorting method based on characteristic reference actions Eur. J. Oper. Res. 2010, 204, 565-580. [CrossRef]

15. Nemery, P.; Lamboray, C. Flow sort: A flow-based sorting method with limiting or central profiles. Top 2008, 16, 90-113. [CrossRef]

16. Macary, F.; Dias, J.A.; Figueira, J.R.; Roy, B. A Multiple Criteria Decision Analysis Model Based on ELECTRE TRI-C for Erosion Risk Assessment in Agricultural Areas. Environ. Model. Assess. 2014, 19, 221-242. [CrossRef]

17. Doumpos, M.; Figueira, J.R. A multicriteria outranking approach for modeling corporate credit ratings: An application of the ELECTRE TRI-NC method. Omega 2019, 82, 166-180. [CrossRef]

18. Kadziński, M.; Tervonen, T.; Rui Figueira, J. Robust multi-criteria sorting with the outranking preference model and characteristic profiles. Omega 2015, 55, 126-140. [CrossRef]

19. Zopounidis, C.; Doumpos, M. PREFDIS: A multicriteria decision support system for sorting decision problems. Comput. Oper. Res. 2000, 27, 779-797. [CrossRef]

20. Biluca, J.; de Aguiar, C.R.; Trojan, F. Sorting of suitable areas for disposal of construction and demolition waste using GIS and ELECTRE TRI. Waste Manag. 2020, 114, 307-320. [CrossRef]

21. Madhooshiarzanagh, P.; Abi-Zeid, I. A disaggregation approach for indirect preference elicitation in Electre TRI-nC: Application and validation. J. Multi Criteria Decis. Anal. 2021, 28, 144-159. [CrossRef]

22. Sarrazin, R.; De Smet, Y.; Rosenfeld, J. An extension of PROMETHEE to interval clustering. Omega 2018, 80, 12-21. [CrossRef]

23. Küçükbay, F.; Sürücü, E. Corporate sustainability performance measurement based on a new multicriteria sorting method. Corp. Soc. Responsib. Environ. Manag. 2019, 26, 664-680. [CrossRef]

24. Özpeynirci, Ö.; Özpeynirci, S.; Mousseau, V. An interactive approach for inverse multiple criteria sorting problem. J. Multi Criteria Decis. Anal. 2021, 28, 160-169. [CrossRef]

25. Nafi, A.; Werey, C. Aide à la décision multicritère pour la hiérarchisation de tronçons d'assainissement dans le cadre d'une gestion patrimoniale. Can. J. Civ. Eng. 2009, 36, 1207-1220. [CrossRef]

26. Ishizaka, A.; Nemery, P. Assigning machines to incomparable maintenance strategies with ELECTRE-SORT. Omega 2014, 47, 45-59. [CrossRef]

27. Greco, S.; Kadziński, M.; Mousseau, V.; Słowiński, R. Robust ordinal regression for multiple criteria group decision: UTA GMS-GROUP and UTADIS GMS-GROUP. Decis. Support Syst. 2012, 52, 549-561. [CrossRef]

28. Carriço, N.; Covas, D.I.C.; Céu Almeida, M.; Leitão, J.P.; Alegre, H. Prioritization of rehabilitation interventions for urban water assets using multiple criteria decision-aid methods. Water Sci. Technol. 2012, 66, 1007-1014. [CrossRef] [PubMed]

29. Zopounidis, C.; Doumpos, M. Multicriteria classification and sorting methods: A literature review. Eur. J. Oper. Res. 2002, 138, 229-246. [CrossRef]

30. Figueira, J.; Greco, S.; Roy, B.; Słowiński, R. An Overview of ELECTRE Methods and their Recent Extensions. J. Multi Criteria Decis. Anal. 2013, 20, 61-85. [CrossRef]

31. Fernandez, E.; Navarro, J.; Olmedo, R. Characterization of the Effectiveness of Several Outranking-Based Multi-Criteria Sorting Methods. Int. J. Inf. Technol. Decis. Mak. 2018, 17, 1047-1084. [CrossRef]

32. Mailly, D.; Abi-Zeid, I.; Pepin, S. A multi-criteria classification approach for identifying favourable climates for tourism. J. Multi Criteria Decis. Anal. 2014, 21, 65-75. [CrossRef] 
33. Alvarez, P.A.; Ishizaka, A.; Martínez, L. Multiple-criteria decision-making sorting methods: A survey. Expert Syst. Appl. 2021, 183, 115368. [CrossRef]

34. Brans, J.P. L'ingénièrie de la décision; Elaboration d'instruments d'aide à la décision. La méthode PROMETHEE. In L'Aide à la Décision: Nature, Instruments et Perspectives d'Avenir; Nadeau, R., Landry, M., Eds.; Presses de l'Université Laval: Québec, QC, Canada, 1982; pp. 183-213.

35. Ishizaka, A.; Nemery, P. Multi-Criteria Decision Analysis: Methods and Software; John Wiley \& Sons, Ltd.: Hoboken, NJ, USA, 2013; ISBN 978-1-119-97407-9.

36. Brans, J.P.; Vincke, P. Note-A Preference Ranking Organisation Method. Manage. Sci. 1985, 31, 647-656. [CrossRef]

37. Papathanasiou, J.; Ploskas, N. Multiple Criteria Decision-Aid Methods (Mcda); Springer: Berlin/Heidelberg, Germany, 2018; pp. 57-76. ISBN 978-3-319-91646-0.

38. Brans, J.P.; Vincke, P.; Mareschal, B. How to select and how to rank projects: The PROMETHEE method. Eur. J. Oper. Res. 1986, 24, 228-238. [CrossRef]

39. Dias, L.; Mousseau, V. Eliciting multi-criteria preferences: ELECTRE models. Int. Ser. Oper. Res. Manag. Sci. 2018, 261, 349-375. [CrossRef]

40. Roy, B. The outranking approach and the foundations of electre methods. Theory Decis. 1991, 31, 49-73. [CrossRef]

41. Mousseau, V. Eliciting Information Concerning the Relative Importance of Criteria. In Advances in multicriteria analysis; Springer: Boston, MA, USA, 1995; pp. 17-43. [CrossRef]

42. Bana e Costa, C.A.; Vansnick, J.C. MACBETH-An interactive path towards the construction of cardinal value functions. Int. Trans. Oper. Res. 1994, 1, 489-500. [CrossRef]

43. Dias, L.; Mousseau, V.; Figueira, J.; Clímaco, J. An aggregation/disaggregation approach to obtain robust conclusions with ELECTRE TRI. Eur. J. Oper. Res. 2002, 138, 332-348. [CrossRef]

44. Doumpos, M.; Zopounidis, C. Preference disaggregation and statistical learning for multicriteria decision support: A review. Eur. J. Oper. Res. 2011, 209, 203-214. [CrossRef]

45. Somisetti, V.S.S.; Palla, S.H. Efficient Clustering of Water Distribution Network Using Affinity Propagation. Ingénierie Des Systèmes D'information 2020, 25, 505-513. [CrossRef]

46. Frey, B.J.; Dueck, D. Clustering by passing messages between data points. Science 2007, 315, 972-976. [CrossRef]

47. Dueck, D.; Frey, B.J. Non-metric affinity propagation for unsupervised image categorization. In Proceedings of the 11th International Conference on Computer Vision, Rio de Janeiro, Brazil, 14-21 October 2007. [CrossRef]

48. Carriço, N.; Ferreira, B. Data and Information Systems Management for the Urban Water Infrastructure Condition Assessment. Front. Water 2021, 3, 1-5. [CrossRef]

49. Rossman, L.; Woo, H.; Tryby, M.; Shang, F.; Janke, R.; Haxton, T. EPANET 2.2 User Manual; U.S. Environmental Protection Agency: Washington, DC, USA, 2020.

50. Klise, K.A.; Bynum, M.; Moriarty, D.; Murray, R. A software framework for assessing the resilience of drinking water systems to disasters with an example earthquake case study. Environ. Model. Softw. 2017, 95, 420-431. [CrossRef] [PubMed]

51. Coelho, S. Performance in Water Distribution-A System Approach; Research Studies Press Ltd.: Baldock, UK; ISBN 0863802192.

52. Coelho, S.; Alegre, H. Indicadores do Desempenho de Sistemas de Saneamento Básico; LNEC: Lisboa, Portugal, 1999.

53. Caetano, J.; Regina, C.; Monteiro, L.; Covas, D. Using hydraulic and water quality models as decision support tools in a water utility. In Proceedings of the 14th International CCWI Conference (Computing and Control for the Water Industry), Amsterdam, The Netherlands, 7-9 November 2016.

54. D’Ercole, M.; Righetti, M.; Raspati, G.S.; Bertola, P.; Ugarelli, R.M. Rehabilitation planning of water distribution network through a reliability-based risk assessment. Water 2018, 10, 277. [CrossRef]

55. Wagner, B.J.M.; Shamir, U.; Marks, D.H. Water distribution reliability: Simulation methods. J. Water Resour. Plan. Manag. 1988, 114, 276-294. [CrossRef]

56. Creaco, E.; Franchini, M. Fast network multi-objective design algorithm combined with an a posteriori procedure for reliability evaluation under various operational scenarios. Urban Water J. 2012, 9, 385-399. [CrossRef]

57. Puust, R.; Kapelan, Z.; Savic, D.A.; Koppel, T. A review of methods for leakage management in pipe networks. Urban Water J. 2010, 7, 25-45. [CrossRef]

58. ERSAR. Water and Waste Services Quality Assessment Guide: 2nd Generation of the Assessment System; ERSAR: Lisbon, Portugal, 2017; ISBN 978-989-8360-11-3. 